EDNEI DA ASSUNÇÃO ANTUNES COELHO

\title{
ISOLAMENTO DE FUNGOS COM POTENCIAL PARA BIORREMEDIAÇÃO NA MINA DE URÂNIO OSAMU UTSUMI
}

Tese apresentada ao Departamento de Microbiologia

do Instituto de Ciências Biomédicas da Universidade de São Paulo, para obtenção do Título de Doutor em Ciências.

Área de concentração: Microbiologia

Orientador: Prof. Dr. Benedito Corrêa

Versão original

SÃO PAULO 


\section{RESUMO}

COELHO, E. A. A. Isolamento de fungos com potencial para biorremediação na mina de urânio Osamu Utsumi. 2019. 90p. Tese (Doutorado em: Microbiologia) - Instituto de Ciências Biomédicas, Universidade de São Paulo, São Paulo, 2019.

A mina Osamu Utsumi das indústrias nucleares do Brasil (INB), localizada no município de Caldas/MG, foi a primeira mina de extração de urânio no Brasil e teve suas atividades encerradas em 1995. Desde então apresenta problemas de reabilitação das áreas contaminadas devido aos elevados níveis de contaminação de urânio. Neste sentido, a biorremediação surgiu como tecnologia alternativa para a remediação de locais contaminados com metais pesados. Assim, a presente investigação teve como objetivo geral isolar e caracterizar espécies fúngicas resistentes ao urânio de solo, água e sedimento da mina de urânio Osamu Utsumi e avaliar a capacidade de remoção de urânio por esses microrganismos. $\mathrm{O} \mathrm{pH}$ das amostras de água foi entre 3,16 e 3,48. A concentração de urânio nas amostras foi de 58 a $268 \mathrm{mg} / \mathrm{kg}$ (solo), 1,05 a 4,46 mg/L (água) e 283 a $488 \mathrm{mg} / \mathrm{kg}$ (sedimento). A média de atividade de água ( $A a)$ das amostras de solo foi de 0,97. Das amostras analisadas, foram isolados e idenficados 57 fungos, sendo o gênero Penicillium o mais prevalente. Nos testes de tolerância, 38 \% (22) dos isolados fúngicos foram considerados tolerantes ao urânio, com destaque para 5 isolados de Penicillium piscarium. O índice de velocidade de crescimento micelial (IVCM) revelou crescimento de 48 fungos em elevadas concentrações de urânio (2000mg/L). A Análise da concentração inibitória mínima (CIM) demonstrou o crescimento de 25 fungos em concentrações de $8000 \mathrm{mg} / \mathrm{L}$. Os testes de biossorção, com biomassa viva dos fungos, demonstraram que 11 espécies fúngicas foram consideradas com alto potencial para biorremediação do metal. Ao compararmos os testes de resistência/tolerância com capacidade de biossorção do metal, concluímos que os fungos isolados da mina Osamu Utsumi com alto potencial para biorremediação de urânio foram Gongronella butleri, Penicillium piscarium, Penicillium citrinum, Penicillium ludwigii, Talaromyces amestolkiae.

Palavras-chave: Mina de urânio. Fungos. Biorremediação. Osamu Utsumi. 


\begin{abstract}
COELHO, E. A. A. Isolation of fungi with potential for bioremediation from Osamu Utsumi uranium mine. 2019. 90p. Ph. D. Thesis (Department of Microbiology) - Instituto de Ciências Biomédicas, Universidade de São Paulo, São Paulo, 2019.
\end{abstract}

The Osamu Utsumi mine from Industrias Nucleares do Brasil (INB), located in the city of Caldas/MG, was the first uranium extraction mine in Brazil and closed its activities in 1995. Since then, it has problems in rehabilitating contaminated areas due to high levels of uranium contamination. In this regard, bioremediation emerged as an alternative technology for the remediation of sites contaminated with heavy metals. The aim of the present investigation was to isolated and characterized fungal species resistant to uranium from soil, water and sediment from Osamu Utsumi uranium mine and evaluated the uranium removal capacity from these microorganisms. The $\mathrm{pH}$ of the water samples was between 3.16 and 3.48. The uranium concentration from the samples was 58 to $268 \mathrm{mg} / \mathrm{kg}$ (soil), 1.05 to $4.46 \mathrm{mg} / \mathrm{L}$ (water) and 283 to $488 \mathrm{mg} / \mathrm{kg}$ (sediment). The mean water activity ( $W a$ ) of the soil samples was 0.98 . From the samples, 57 fungi were isolated, with Penicillium being the most frequent species. In the tolerance tests, 38\% (22) of the fungal isolates were considered tolerant to uranium, with emphasis on 5 Penicillium piscarium isolates. The mycelial growth rate revealed growth of 48 fungi at high concentrations of uranium tested $(2000 \mathrm{mg} / \mathrm{L})$. Minimal inhibitory concentration (MIC) analysis showed growth of 25 fungi at concentrations of $8000 \mathrm{mg} / \mathrm{L}$. Biosorption tests with live fungal biomass showed that 11 species were considered as having high potential for bioremediation of the uranium. When comparing the resistance/tolerance tests with uranium biosorption capacity, we concluded that the fungi isolated from the Osamu Utsumi mine with the best potential for uranium bioremediation were Gongronella butleri, Penicillium piscarium, Penicillium citrinum, Penicillium ludwigii, Talaromyces amestolkiae.

Keywords: Uranium mine. Fungi. Bioremediation. Osamu Utsumi. 


\section{INTRODUÇÃO}

\subsection{Mineração}

As atividades de mineração, realizadas de forma sustentável, ainda são de extrema importância para o desenvolvimento econômico. Oferecendo diversas fontes de matéria prima para as indústrias, a mineração foi essencial para o processo interiorização do país. A extração de minérios ajuda no equilíbrio financeiro do Brasil, fazendo parte de mais de $5 \%$ do produto interno bruto (PIB) e, consequentemente, a geração de milhares de empregos de maneira direta e indireta (IBRAM, 2015). Entretanto, as atividades de mineração ainda são marcadas negativamente por apresentarem impactos na saúde pública, com danos locais, regionais e globais ao meio ambiente (SUH et al., 2017). De forma geral, a extração de minérios causa impactos negativos como: supressão da vegetação, exposição do solo aos processos de erosão, contaminação por metais pesados de solo, água, inundações, desmatamento entre outros problemas relacionados a essas atividades (FERRARI, 2010).

Para redução de impactos causados pela atividade de mineração é necessário a realização de estudos levando em consideração todo o ciclo do processo de mineração, com a exploração mineral (pesquisa da jazida), desenvolvimento da mina, lavra e exaustão da jazida (onde se encerra o empreendimento) (CIPRIANI, 2002).

Só a partir dos anos 1970, após a identificação de problemas relacionados às escavações desenfreadas, que começaram a surgir regulamentações das atividades de mineração em vários países do mundo (AGI, 2018). No Brasil, várias minas já estavam em atividade quando passou a vigorar o decreto $\mathrm{n}^{\circ} 97.632$ de 10 de abril de 1989, que criou a obrigatoriedade na recuperação de áreas degradadas, realizando o estudo do impacto ambiental e apresentando o relatório ao órgão ambiental competente (LIMA; FLORES; COSTA, 2006), porém várias empresas não seguiram essas regras.

A falta de regulamentações no passado e de fiscalizações por órgãos competentes dos processos de extração de minérios, podem estar diretamente relacionadas aos problemas que enfrentamos atualmente com os rejeitos de mineração. Temos como exemplo as tragédias ambientais de Mariana e Brumadinho em Minas Gerais, onde após a destruição das barragens de contenção, toneladas de rejeitos de mineração acabaram provocando destruição de locais e danos imensuráveis à vida e ao meio ambiente. 
No Brasil, problemas relacionados à disposição e tratamento de rejeitos são muito frequentes, destacando-se entre as técnicas convencionais utilizadas para remediação a remoção do rejeito para um aterro ou simplesmente "tampar" e conter as áreas contaminadas no local. Essas alternativas apresentam desvantagens, na primeira podem ocorrer problemas nas áreas de escavação com o manuseio e disposição do material perigoso além dos custos do processo, já a segunda alternativa é uma solução provisória, visto que o material permanece no ambiente, o que exige monitoramento e manutenção das barreiras de isolamento entre outros custos e perigos (VIDALI, 2001).

Portanto, devemos considerar que as atividades de mineração apresentam prós e contras, sendo necessários estudos prévios sobre os impactos da extração de minérios, adequada disposição e tratamento de rejeitos, visando reduzir os danos relacionados ao extrativismo mineral.

\subsection{Mina Osamu Utsumi, a primeira mina de extração de urânio do Brasil}

Após a segunda guerra mundial e início da chamada guerra fria, iniciou-se uma corrida visando deter o comércio de tecnologia e minerais provenientes da indústria nuclear (FETTUS; MCKINZIE, 2012). Durante o conselho de segurança das nações unidas (ONU), o Brasil deixou claro a possibilidade de atuar em conjunto com os Estados Unidos, porém o representante do Brasil no conselho Almirante Álvaro Alberto da Mota, entendeu que o plano Baruch (Propostas dos EUA para regulamentação e gestão internacional das atividades atômicas) era uma restrição a soberania e segurança nacional, assim, através da aliança entre militares e cientistas surgiu o Conselho Nacional de Pesquisas (CNPq), marcando o início da história da energia nuclear no Brasil (MARIA; ANDRADE, 2012)

Em 1959, iniciou-se a construção da mina de urânio Osamu Utsumi, com as reservas calculadas em aproximadamente 17.200 toneladas de octóxido de triurânio $\left(\mathrm{U}_{3} \mathrm{O}_{8}\right)$ ou "yellow cake" (SOUZA; SILVEIRA; PEREIRA, 2013). Localizada na região do planalto do município de Caldas/MG, a mina Osamu Utsumi das Indústrias Nucleares do Brasil (INB), a primeira mina de extração de minério de urânio do Brasil, esteve em operação de 1982 a 1995, com produção total de 1.030 toneladas de urânio, bem abaixo do que se esperava extrair (CIPRIANI, 2002; NÓBREGA; LIMA; LEITE, 2008).

Estima-se que os custos totais da implantação da mina foram de U\$ 230 milhões, sendo a escavação realizada pelo processo de decapagem. $\mathrm{O}$ formato circular da cava da 
mina é de aproximadamente 1200 metros de diâmetro por 176 de profundidade (Figura 1) (CIPRIANI, 2002; FAGUNDES, 2008).

Figura 1 - Vista panorâmica da cava da mina Osamu Utsumi. (Foto: Ednei Coelho).

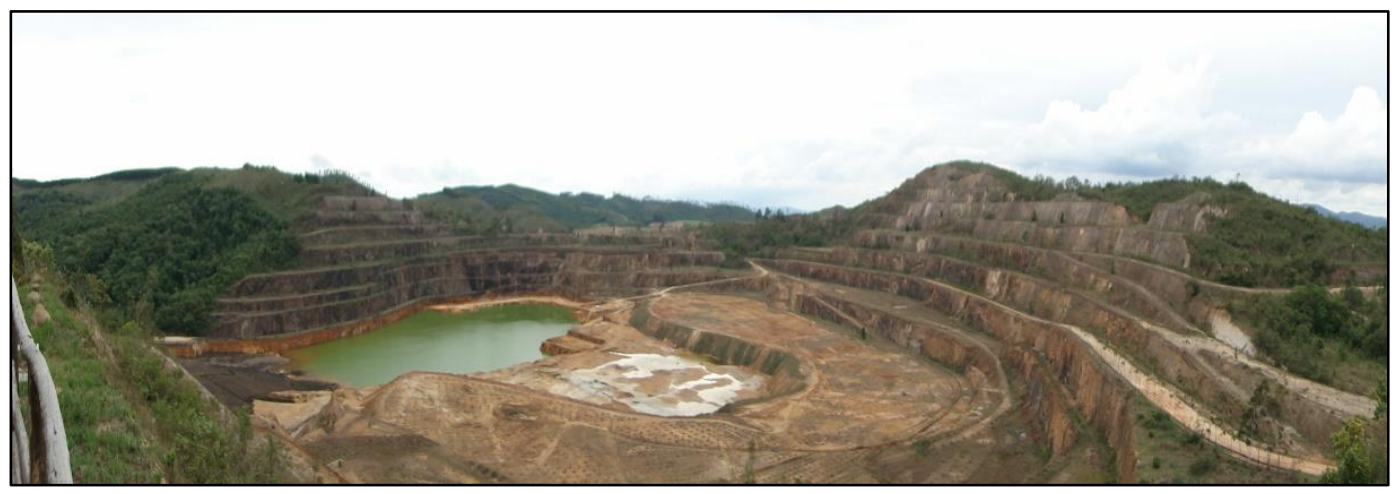

Com o esgotamento das jazidas de Caldas e o descobrimento das reservas de Caetité/BA, a mina Osamu Utsumi encontra-se desde 1995 em fase de descomissionamento. A obrigação fundamental imposta aos titulares de concessão de lavra no Brasil, com relação ao fechamento da mina, é que eles promovam a reabilitação das áreas impactadas pelas atividades de mineração de acordo com o PRAD (Plano de Recuperação de Áreas Degradadas) previamente elaborado e aprovado pelo órgão governamental competente, porém, no caso da mina Osamu Utsumi, isso não aconteceu pois a legislação só entrou em vigor após a mina estar em funcionamento (DUTRA et al. 2013).

Depois de identificado o problema causado pela extração de urânio na área da mina, em fevereiro de 2004, o Instituto Brasileiro do Meio Ambiente e dos Recursos Naturais Renováveis (IBAMA) juntamente com a Comissão Nacional de Energia Nuclear (CNEN) firmou um termo de referência para elaboração e apresentação do PRAD para o complexo minero-industrial da cidade de Caldas/MG, operação voltada para tentar deixar as condições da região da mina o mais próximo possível da existente antes do início da sua implantação, com a remediação, reflorestamento, restauração do local (LIMA; FLORES; COSTA, 2006; NÓBREGA; LIMA; LEITE, 2008).

Com a ausência de legislações rigorosas sobre a exploração do minério no Brasil, na época da implantação da mina de urânio, não houve um controle adequado na disposição de rejeitos (SOUZA; SILVEIRA; PEREIRA, 2013). 
Durante a exploração da jazida de urânio, o material oriundo da decapagem da mina, caracterizado inicialmente como estéril, era encaminhado aos locais conhecidos como "bota-foras" (BFs), esses são chamados de BF-4 e BF-8 com volume de 12,4 e 14,8 milhões de $\mathrm{m}^{3}$ de rejeitos, respectivamente, e altura de 90 metros (Figura 2) (CIPRIANI, 2002; SOUZA; SILVEIRA; PEREIRA, 2013).

Figura 2 - Vista parcial da pilha de rejeitos Bota-fora 4. (Foto: Ednei Coelho).

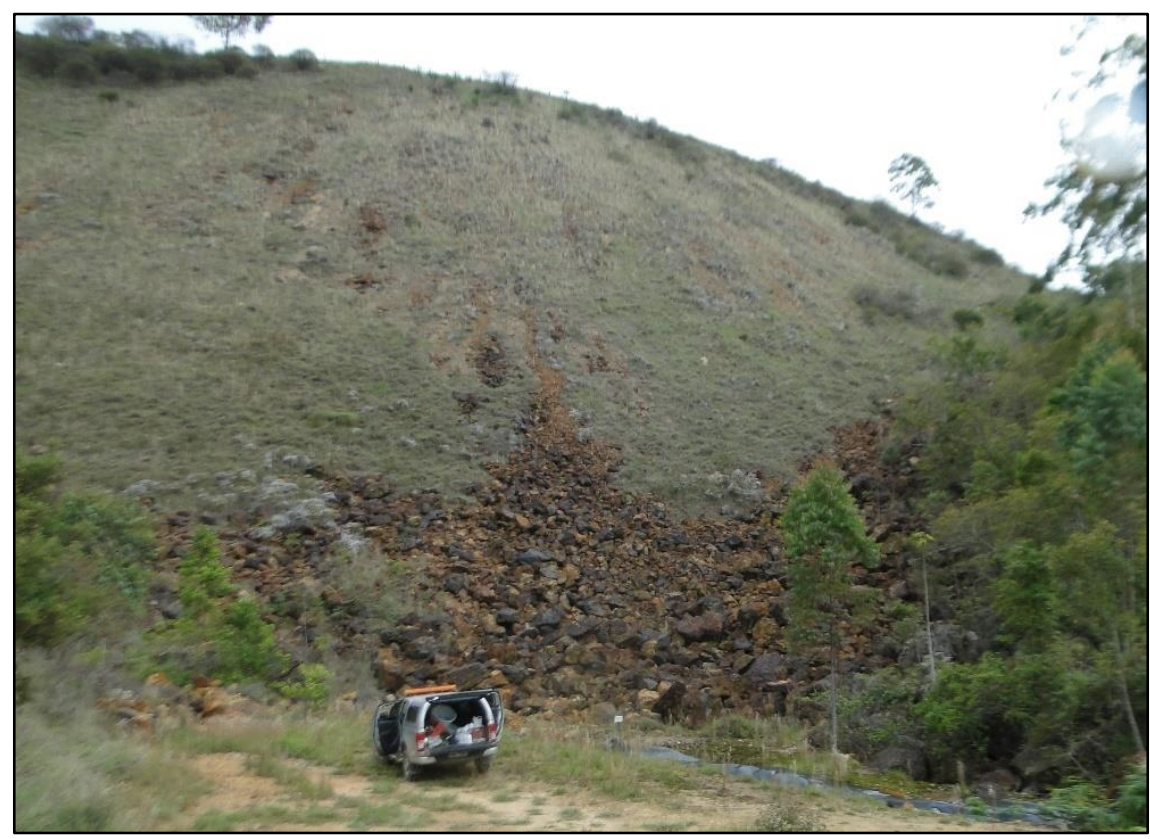

A disposição das pilhas de rejeitos originou a formação de montanhas de rochas que podem estar diretamente relacionados a formação de drenagem ácida de mina (DAM), aumentando a concentração de metais pesados e radionuclídeos em rios e lagos na área da mina e proximidades (FAGUNDES, 2008).

\subsubsection{Drenagem ácida de mina}

O principal problema enfrentado pela INB-Caldas para recuperação na região onde funcionava a mina é a drenagem ácida de mina (DAM).

A DAM, é basicamente causada pela exposição de rochas ao oxigênio. Quando a água da chuva, por exemplo, invade as pilhas de rejeitos de mineração, ocorre a interação entre oxigênio, água e sulfetos metálicos, esse processo leva a formação de ácido sulfúrico. O ácido sulfúrico então dissolve os metais pesados das rochas, e a água ácida 
com metais (efluentes) se espalha por toda parte contaminando rios, lagos e lençóis freáticos, causando a morte de animais e plantas (Figura 3) (AKCIL; KOLDAS, 2006; FAGUNDES, 2008).

Figura 3 - Ilustração mostra como ocorre a drenagem ácida de mina (DAM)

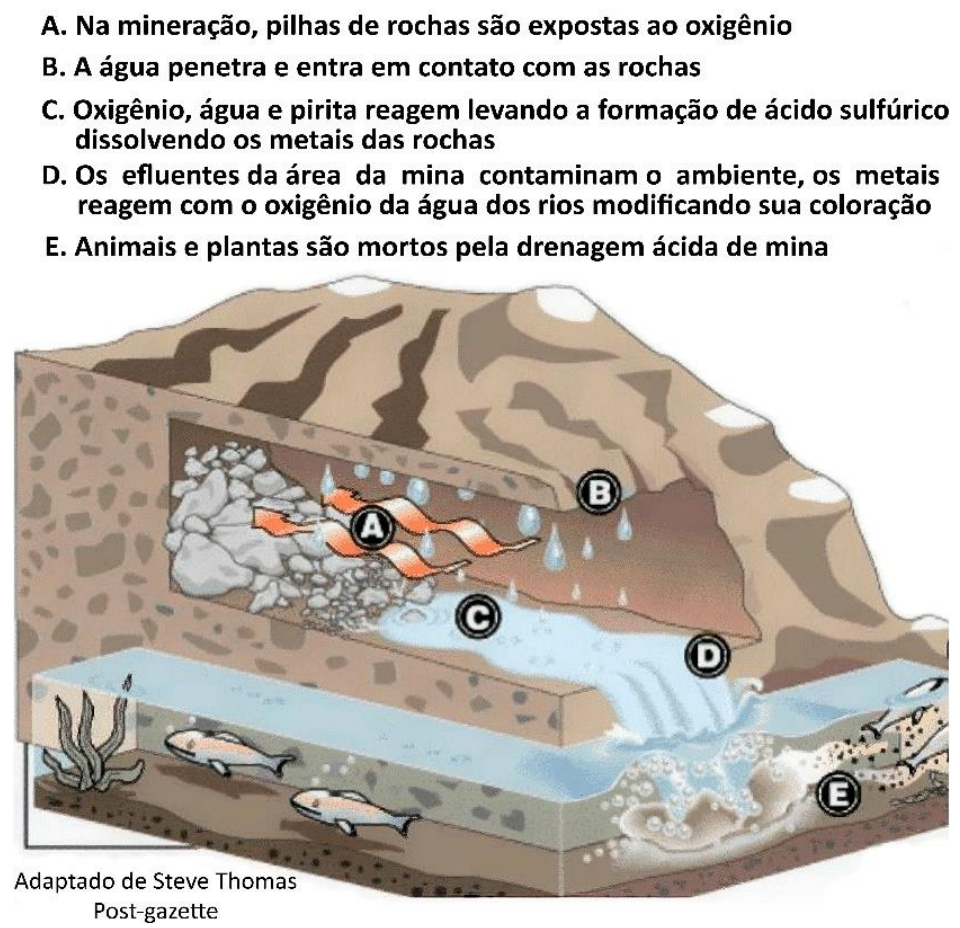

Os microrganismos ambientais podem também causar a oxidação dos sulfetos metálicos (MARTINS et al. 2004). Na área da mina Osamu Utsumi, a grande concentração de pirita $\left(\mathrm{FeS}_{2}\right)$ nos Bota-foras é a principal responsável pela acidez da água (SOUZA; SILVEIRA; PEREIRA, 2013).

A DAM pode gerar efluentes com altas concentrações de metais pesados, a formação de ácido sulfúrico eleva a acidez da água com pH entre 2 e 3 , solubilizando metais pesados e radionuclídeos, comprometendo a qualidade dos recursos hídricos da região afetada (LYEW; SHEPPARD, 1997; NÓBREGA; LIMA; LEITE, 2008). Os BFs da mina Osamu Utsumi tem contribuição importante na geração de DAM (NÓBREGA; LIMA; LEITE, 2008).

Todo o processo de DAM pode causar mudanças na coloração da água, devido aos processos de oxidação, impossibilitando o consumo por animais e seres humanos. Quando o $\mathrm{pH}$ da água está entre 3,5 e $4 \mathrm{o} \mathrm{Fe}^{3+}$ é precipitado em hidróxido de ferro 
$\mathrm{Fe}(\mathrm{OH})_{3}$, o que causa a coloração alaranjada da água (ROYCHOWDHURY; SARKAR; DATTA, 2015), esse processo pode ser observado nas bacias formadas na área da mina Osamu Utsumi (Figura 4) .

Figura 4 - Bacia BIA localizada na mina de urânio Osamu Utsumi. (foto: Ednei Coelho).

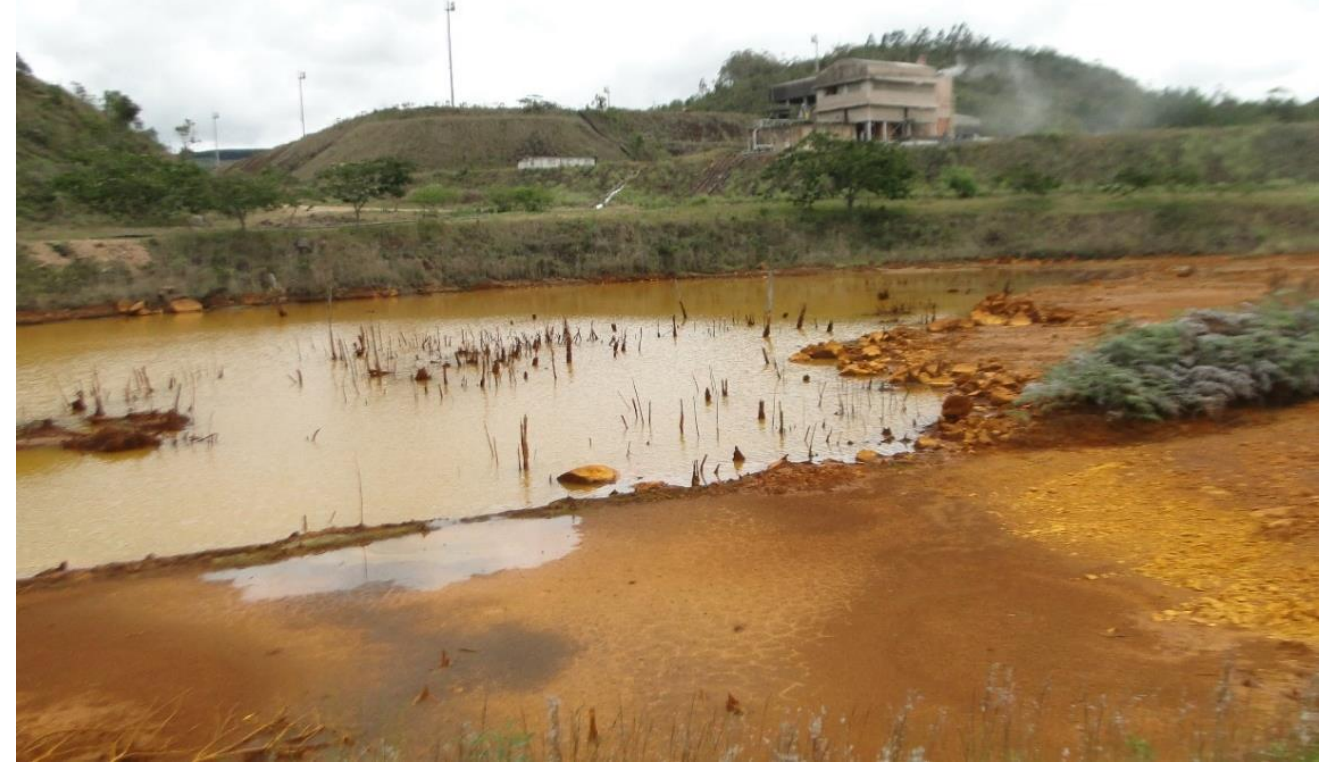

Após constatado o problema com a DAM na mina, o CNEN determinou que o tratamento das águas fosse obrigatório. Atualmente o tratamento químico é executado na estação de tratamento de águas marginais da mina (Figura 5), elevando o pH da água é utilizado hidróxido de cálcio, os floculantes auxiliam a etapa de separação sólido-líquido, esse tratamento gera um precipitado de lama alcalina e escura conhecida como diuranato de cálcio (DUCA), que é depositado na cava da mina há mais de 20 anos, a cava, por sua vez, encontra-se inundada de água ácida (FAGUNDES, 2008; FERRARI, 2010; GOMES; LADEIRA, 2011). Segundo os técnicos da mina o gasto anual com o tratamento de água contaminada é de R $\$ 2$ milhões.

$\mathrm{Na}$ área da mina outros tipos de tratamento vêm sendo estudados e implantados, com o objetivo de controlar a contaminação do ambiente pelos metais. Uma das ideias é a utilização de ozônio para descontaminação de solo e água, sendo o ozônio um gás que pode oxidar os metais pesados existentes na água, e no solo a ideia é injetar ozônio nas montanhas de rejeitos (bota-foras) eliminando as bactérias que oxidam os sulfetos metálicos. Porém, a viabilidade desses processos é bastante discutida, pois poderia gerar 
um alto consumo muito alto de energia na produção de ozônio e não se sabe se seria possível injetar ozônio nas imensas pilhas de rejeitos.

Figura 5 - Estação de tratamento de águas da mina de urânio Osamu Utsumi. (Foto: Ednei Coelho).

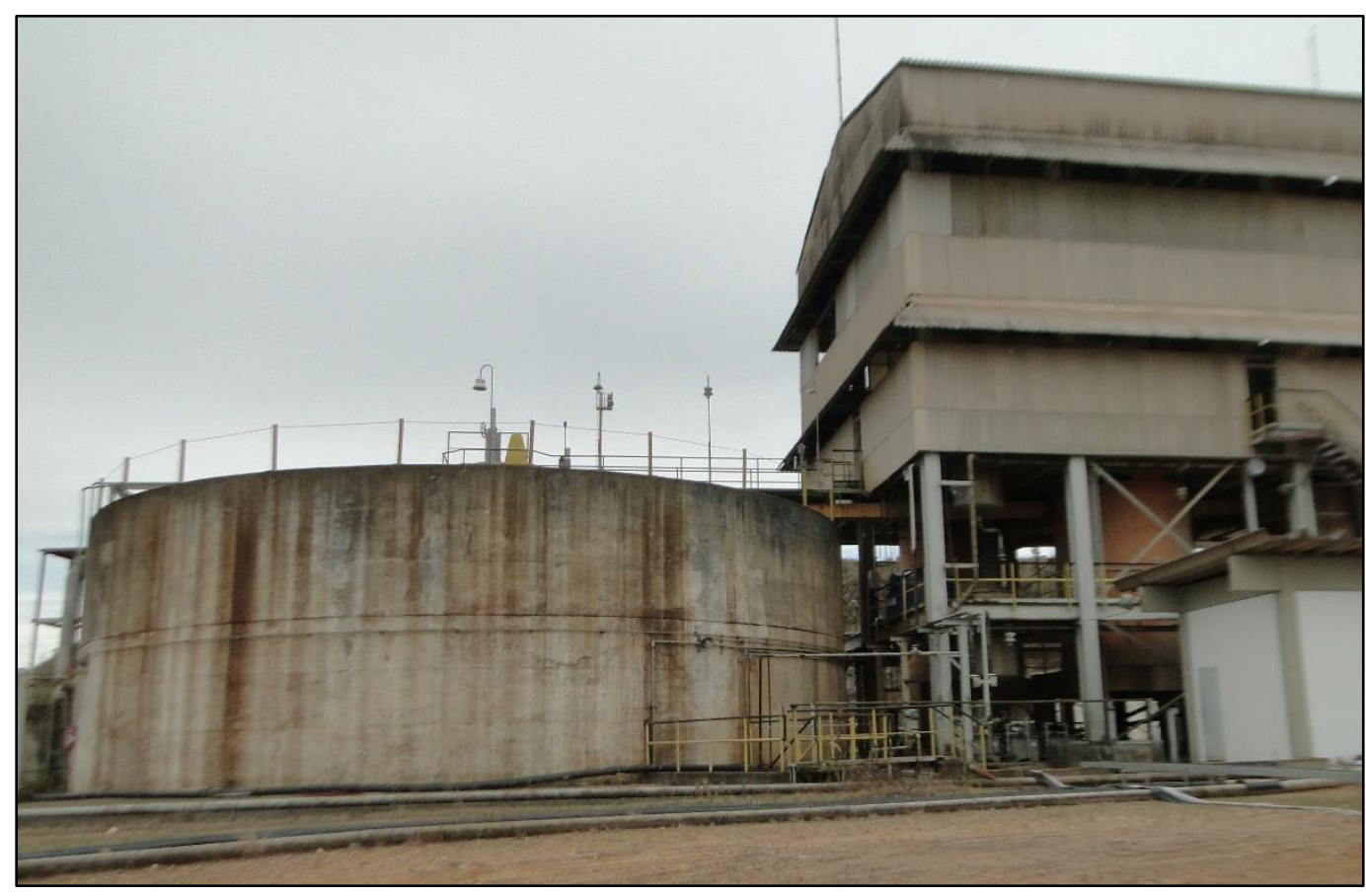

O tratamento da água utilizando resinas no sistema de coluna de troca iônica também está sendo estudado e implantado (Figura 6), neste caso, o sulfato de urânio se adere a resina porosa que possuem cargas eletrostáticas, quando ocorre a saturação da resina é realizada a eluição do urânio com amônia ou sódio, formando diuranato de amônio ou sódio, que são colocados em tambores e enviados para a INB Caetité/BA, onde o urânio é purificado. Esse processo pode gerar até 13 toneladas de urânio por ano, isso não é interessante, pois o objetivo é o fechamento total da mina. 
Figura 6 - Colunas de troca iônica na estação de tratamento da mina Osamu Utsumi. (Foto: Ednei Coelho).

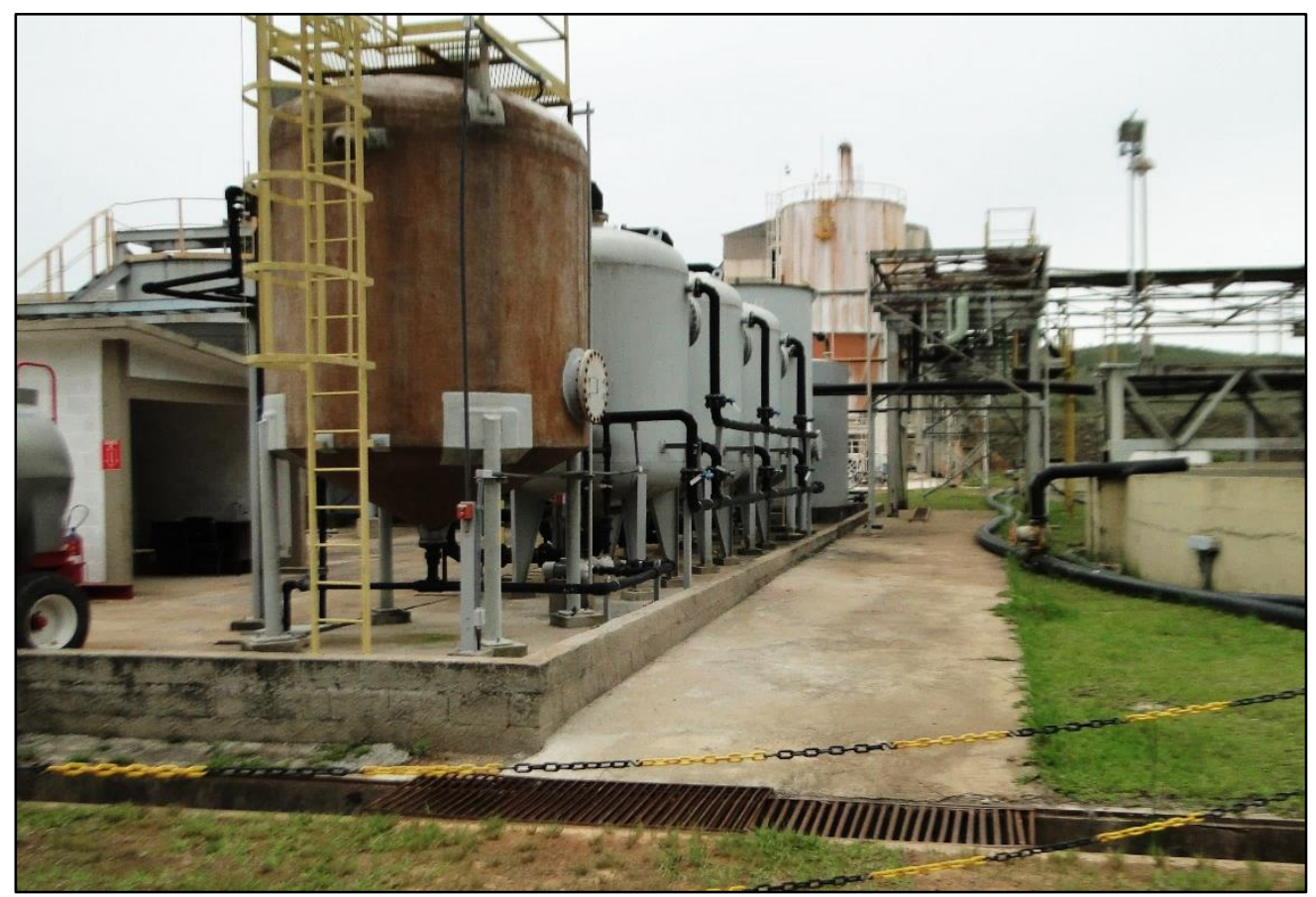

De acordo com Elbaz-Poulichet et al. (1999) e Poston et al. (1984), as atividades de mineração podem levar ao aumento de metais pesados e radionuclídeos, como o urânio, em águas naturais.

\subsection{Metais pesados}

Dentre os vários agentes poluentes do ambiente de mineração, os metais pesados recebem atenção especial, uma vez que alguns são extremamente tóxicos para uma grande variedade de organismos, mesmo em quantidades muito baixas, pois são elementos muito reativos e bioacumuláveis nos organismos vivos (ELDERFIELD; UPSTILLGODDARD; SHOLKOVITZ, 1990; GOMES; MENDONCA-HAGLER; SAVVAIDIS, 1998; NIES, 1999; RAHMAN et al. 2002; SILVA, 2009; VALDMAN; LEITE, 2000).

O termo "metal pesado" é arbitrário e impreciso. Raskin et al. (1994), por uma questão de simplicidade, definiram como metal pesado qualquer elemento com 
propriedade metálica (ductilidade, densidade, condutividade) e um número atômico maior que 20 .

Em muitos casos, os metais pesados são definidos como aqueles que apresentam uma alta densidade, superior a $5 \mathrm{~g} / \mathrm{cm}^{3}$, e que mesmo em baixas concentrações são tóxicos (JÄRUP, 2003). Essa definição atualmente ainda é muito discutida, pois alguns metais "leves" ou metaloides também são tóxicos, assim como alguns com alta densidade não apresentam toxicidade, por exemplo o ouro não é considerado tóxico, mas apresenta um número atômico 79 e densidade $19,32 \mathrm{~g} / \mathrm{cm}^{3}$. Uma classificação biologicamente relevante de metais pesados, conforme sua toxicidade e propriedades químicas precisa ser proposta (DUFFUS, 2002).

Em alguns metais, a toxicidade vai depender do seu estado alotrópico ou oxidativo, por exemplo, o crômio hexavalente é altamente letal, principalmente por suas propriedades cancerígenas, enquanto o crômio trivalente é significativamente nutricional para vários organismos, inclusive para os humanos (WUNDERLIN, 2018).

Em alguns casos, vários metais pesados são micronutrientes, e assim essenciais para sistemas biológicos e devem estar presentes em baixas concentrações (níveis adequados), assim fornecem cofatores essenciais para proteínas e enzimas, como por exemplo o ferro. Porém, em concentrações elevadas ou se ingeridos a longo prazo, os metais pesados podem se tornar tóxicos, bloqueando grupos funcionais, deslocando outros íons metálicos ou modificando a atividade biológica das moléculas (BHAT; KHAN, 2011; COLLINS; STOTZKY, 1989; GARBISU; ALKORTA, 2003).

\subsubsection{Urânio}

O urânio (U) é um metal denso $\left(19,1 \mathrm{~g} / \mathrm{cm}^{3}\right)$ que possui baixa radioatividade e é naturalmente encontrado em rochas, solo, água, ar, plantas e animais. O U apresenta um número atômico 92, sendo encontrado na natureza em pequenas concentrações em partes por milhão, porém quando a quantidade encontrada é grande suficiente o metal é então comercialmente extraído (ROBERTS, 2012).

Após a remoção do urânio do solo, as rochas são trituradas e, dependendo de como será o processo, soluções químicas (como solventes) são utilizadas para separação do metal de outras substancias indesejadas (SPOON, 2019). O metal é inicialmente separado em dióxido de urânio $\left(\mathrm{UO}_{2}\right)$, ou em outras formas químicas, através de uma série de processos químicos conhecidos como "moagem do minério", esses processos buscam a 
obtenção do "yellow cake" ou urânio concentrado, os remanescentes da moagem, chamados de rejeitos, são coletados e armazenados (USNRC, 2017).

$\mathrm{O}$ urânio natural $\left(\mathrm{UO}_{2}\right)$ é amplamente distribuído na natureza, está presente em cerca de 160 minerais como a uranita, cleveite, becquerelite, autunita, carnotita e pechblenda, e é constituído por três isótopos alfa: ${ }^{238} \mathrm{U}(99,2745 \%),{ }^{235} \mathrm{U}(0,7200 \%)$ $\mathrm{e}^{234} \mathrm{U}(0,0054 \%)$ (OLSZEWSKI; BORYŁO; SKWARZEC, 2015).

Devido à alta capacidade de mobilização do metal no ambiente por carbonatos e fosfatos o teor de urânio presente na natureza pode variar. Em rochas, solo e sedimento $\mathrm{O}{ }^{238} \mathrm{U}$ e ${ }^{234} \mathrm{U}$ estão relativamente em equilíbrio, ou seja, no ambiente natural não estão em seu estado radioativo (MEINRATH; SCHNEIDER; MEINRATH, 2003; OLSZEWSKI; BORYŁO; SKWARZEC, 2015).

Com a manipulação dos isótopos de $\mathrm{U}$ podem ser obtidas variações menos radioativas, como o ${ }^{238} \mathrm{U}$ que podem ser utilizadas na produção de projéteis (munições) ou blindagens de tanques de guerra e aviões, sendo esse composto até 2 vezes mais pesado que o aço, ou a variação mais radioativa $\left({ }^{235} \mathrm{U}\right)$ "físsil" que é utilizada na produção de armas e em usinas nucleares (HARDER, 2019).

A concentração de urânio no ambiente pode ser também elevada devido às atividades humanas, como utilização de fertilizantes fosfatados na agricultura, resíduos industriais ou utilização para fins militares (OHJ, 2012).

\subsubsection{Dispersão de urânio no ambiente}

A proximidade do urânio com fontes de água é o principal fator responsável pela dispersão do metal pesado no ambiente, sua dispersão depende do seu estado oxidativo, o qual pode ser hexavalente U(VI) ou tetravalente U(IV). O U(VI) apresenta alta solubilidade em água, principalmente em condições ácidas, já em seu estado reduzido o U(IV) é basicamente "imóvel" e insolúvel e com baixa toxidade, pois a sua disponibilidade para os organismos é reduzida (GAD, 2017).

Sob condições redutoras, o urânio é imobilizado, principalmente na presença de quantidades significativas de fosfato, cálcio, sulfato e potássio, onde ocorre a formação de compostos estáveis e complexos sendo o metal precipitado no meio (ELLESS; LEE, 1998).

Em solo, sedimento e água o urânio é sensível aos processos corrosivos, sendo transformado na sua forma solúvel U(VI), como por exemplo sulfato de urânio (U(SO $\left.\mathrm{SO}_{4}\right)_{2}$. 
Os seres humanos são afetados através da ingestão de alimentos, consumo de água contaminada ou inalação, sendo a água a fonte de contaminação mais significativa (KURTTIO et al. 2002; SILVA; SOUZA; AMARAL, 2003).

\subsubsection{Toxicidade do urânio}

Devido à baixa radioatividade do urânio natural, os efeitos a saúde são geralmente atribuídos às suas propriedades químicas e não radioativas (NRC, 2012).

O U solúvel em água é caracterizado pelo seu potencial tóxico, é prejudicial aos organismos aquáticos, plantas e humanos, assim como todos os organismos expostos aos efluentes que são procedentes de minas de urânio (CUMBERLAND et al. 2016).

Os estudos sob os efeitos químicos do urânio em humanos ainda são escassos, porém sabe-se que a ingestão de $200 \mathrm{~mL}$ água contendo $1 \mathrm{~g}$ de nitrato de urânio causa como efeito agudo náuseas, vômito e diarreia (BUTTERWORTH, 1955).

Estudos sugerem que os humanos são menos sensíveis aos efeitos do urânio, sendo indicada uma ordem de sensibilidade aos seus efeitos de: coelhos>camundongos>porcos>ratos>cães>gatos e humanos (VICENTE-VICENTE et al. 2010).

$\mathrm{Na}$ Índia, em vilarejos existentes próximos de áreas de mina de urânio, foram realizados estudos com crianças com idade entre 6-12 anos, essas crianças viviam expostas à água contaminada com urânio, os resultados revelaram alterações no esmalte dos dentes, atraso no crescimento dos dentes, comparado às crianças que não vivem em regiões próximas à mina (KAR; SHETTY; HEGDE, 2016; SHETTY; HEGDE; KAR, 2016).

Também na Índia, um paciente de 12 anos apresentou diminuição na produção de urina e fortes dores nas articulações, acreditava-se inicialmente que se tratava de diabetes, após serem esgotadas todas as hipóteses, foi diagnosticada uma intoxicação causada pela ingestão de água contaminada com urânio. Foi realizada cirurgia para a remoção dos rins, porém as dores nas articulações continuaram, foi detectado posteriormente um osteossarcoma, um tipo de câncer ósseo, possivelmente causado pelo acumulo do U nos rins (PANNU; SUKHMANI; GILL, 2015).

Os seres humanos também podem ser contaminados por urânio através da ingestão de alimentos, principalmente raízes tuberosas como batata e nabo. A quantidade de urânio nesses dependerá da concentração do metal no local em que foram cultivados. Nestes 
locais, a ingestão humana diária de $\mathrm{U}$ é estimada em até 1 micrograma de $\mathrm{U}$ por dia ( $\mu \mathrm{g} / \mathrm{dia})($ ATSDR, 2019).

Na maioria das vezes, o urânio ingerido e inalado, não é absorvido, mais de $90 \%$ é eliminado do corpo através das fezes ou urina, em alguns casos, quando inalado, pode permanecer nos pulmões por longos períodos (VDH, 2016).

Quase 66\% do U absorvido permanece depositado na superfície dos ossos, por até 200 dias, e vai sendo lentamente distribuído para a medula óssea, podendo causar leucemia e diminuição da resposta imune, também pode acumular-se no fígado (16\%) e rins (8\%) e causar danos nesses órgãos (ATSDR, 2019; CAPPELLO; MACARIO, 2019).

Estudos sugerem uma forte correlação entre os ambientes com altas concentrações urânio e a alta prevalência de leucemia em pessoas que vivem próximas destas áreas, principalmente por causa do consumo de água de poço, carne de animais e inalação de poeira (WINDE; ERASMUS; GEIPEL, 2017).

Alterações na histologia pulmonar foram observadas em camundongos expostos por 5 semanas a $10 \mathrm{mg} / \mathrm{U} / \mathrm{m}^{3}$ de nitrato de urânio (WHO, 2018). O urânio também pode afetar as funções o fígado alterando funções hepáticas, como o metabolismo de ácidos biliares (GUÉGUEN et al. 2006).

Através da alimentação, camundongos foram submetidos a baixas $(0,05 \mathrm{mg}$ U/kg/dia) e altas (7000 mg U/kg/dia) concentrações de urânio, em ambos os casos foram detectadas lesões nos rins. Em baixas concentrações ocorreram lesões microscópicas no epitélio tubular e nas altas, as lesões aumentaram e causaram necrose após 30 dias de experimento (MAYNARD; HODGE, 1949).

\subsubsection{Contaminação de urânio na mina Osamu Utsumi}

Dados de monitoramento de água nas áreas próximas da mina Osamu Utsumi demonstraram aumento no teor urânio e outros metais pesados, como o ferro, em córregos e bacias hidrográficas os níveis de concentração estavam acima dos limites estabelecidos na resolução do Conselho Nacional do Meio Ambiente (CONAMA n 357/05) alterada pela Resolução no 410/2009 e 430/2011. Esta resolução dispõe sobre a classificação de corpos de água e diretrizes para seu enquadramento e condições padrões de lançamento de efluentes (CNEN, 2012; LADEIRA; GONÇALVES, 2007; NASCIMENTO; FATIBELLO-FILHO; TEIXEIRA, 2004; NÓBREGA; LIMA; LEITE, 2008). 
De acordo com a resolução do CONAMA, a água proveniente dos rios próximos da área da mina são classificadas em classe II, podendo ser usada para recreação, agricultura, irrigação e consumo humano, após um tratamento simples, neste caso o limite máximo de urânio permitido é de 0,02 mg/L (PEDROBOM et al. 2017).

Atualmente o tratamento de urânio em ambientes contaminados é realizado através de métodos químicos e físicos, alguns exemplos são a extração cromatográfica, precipitação química, coluna de troca iônica. Esses métodos têm aplicações limitadas, pois não apresentam muita eficiência quando o urânio solúvel em água (VI) está em concentrações de 1 a 100 ppm (YANG et al. 2012).

A descontaminação dos ambientes aquáticos por metais pesados necessita de soluções alternativas, como a biorremediação. A utilização de fungos como agentes biorremediadores de contaminantes do solo e água vêm sendo estudada, os fungos apresentam alta capacidades metabólicas que podem ser aplicadas aos metais pesados poluentes do ambiente (HÖLKER; FAKOUSSA; HÖFER, 1995; PAOLETTI, 1999; PEINTNER; MOSER, 1996).

\subsection{Biorremediação}

Em 1930 Tausz e Donath apresentaram ao mundo a ideia de utilizar microrganismos para a descontaminação de solos contaminados com petróleo, dando origem aos processos de biorremediação. Atualmente a biorremediação é utilizada para restauração de ambientes contaminados por substâncias xenobióticas (DZIONEK; WOJCIESZYŃSKA; GUZIK, 2016).

A biorremediação é uma tecnologia ecologicamente correta, não invasiva e promissora que utiliza o potencial metabólico de microrganismos para a recuperação ou redução a níveis aceitáveis de metais pesados em locais contaminados. É considerada uma solução permanente que pode levar a degradação ou transformação de contaminantes ambientais em inofensivos ou menos tóxicos. O processo pode provocar modificações químicas, físicas, bioquímicas ou microbiológicas no ambiente (DZIONEK; WOJCIESZYŃSKA; GUZIK, 2016; EPA, 2013; WATANABE, 2001).

Os processos de biorremediação, diferente dos tradicionais, apresentam baixo custo, baixas manipulação tecnológica, e geralmente alta aceitação da sociedade (VIDALI, 2001). Várias técnicas de biorremediação estão sendo estudadas e descritas, 
porém devido à natureza e variabilidade dos agentes contaminantes no ambiente, não há uma única tecnologia que sirva para todos os poluentes (VIDALI, 2001).

A biorremediação pode ser realizada ex situ ou in situ, o tratamento ex situ requer geralmente um custo um pouco maior, pois ocorre a retirada e transporte dos agentes contaminantes, que serão tratados (descontaminados) em outros locais como estações de tratamento. Os "wetlands" são exemplos de tecnologia ex situ, é uma tecnologia de baixo investimento e ecologicamente correta, onde plantas e microrganismos presentes nesses locais ajudam no tratamento de água contaminada com metais pesados (CHENG et al. 2002).

O tratamento in situ é realizado no local da contaminação, ou seja, não requer transporte ou escavação do local, a baixa logística diminui os custos do processo o que o torna mais viável e com interferência mínima no local (AZUBUIKE; CHIKERE; OKPOKWASILI, 2016).

Como mencionado anteriormente, uma alternativa tradicional é apenas "tampar e estocar" o resíduo, com essa atividade o resíduo continua no ambiente, mas os processos de biorremediação in situ estão sendo estudados para substituir essas técnicas tradicionais (GRÄFE; KLAUBER, 2011).

Existem 3 principais tipos de biorremediação in situ com microrganismos, que são atenuação natural, bioestimulação e bioaumento (SAFDARI et al. 2018).

A atenuação natural está relacionada às atividades dos microrganismos que estão naturalmente presentes no ambiente, permitindo que o ecossistema volte a sua condição original, ocorrendo assim a redução da mobilidade, massa ou mobilidade do agente tóxico, os exemplos são: biossorção, bioprecipitação e biodegradação (SCOW; HICKS, 2005). Entretanto, esse processo natural pode durar muitos anos, principalmente quando a população de microrganismos presentes naturalmente no ambiente não é grande suficiente, assim, visando potenciar a biorremediação ocorre a bioestimulação.

$\mathrm{Na}$ bioestimulação, ocorre a adição de nutrientes e/ou oxigênio que irão auxiliar no crescimento e desenvolvimento dos microrganismos no ambiente contaminado (VIDALI, 2001).

Alguns compostos nutrientes, como adubo, palha de arroz e espiga de milho ou receptores de elétrons como fosfatos, nitrogênio, carbono podem ser introduzidos ao ambiente e utilizados como bioestimuladores (HAMDI et al. 2007; PIMMATA; REUNGSANG; PLANGKLANG, 2013; SUJA et al. 2014). 
No bioaumento, microrganismos isolados do próprio local contaminado ou de outros ambientes contaminados têm sua população aumentada, assim são reinjetados ou introduzidos na região contaminada como inóculos livres ou imobilizados. Para que esse processo seja efetivo o microrganismo precisa ser resistente ao agente contaminante, e conseguir competir com outras espécies no ambiente, principalmente por nutrientes, além é claro de ser capaz de degradar e/ou biorremediar o composto xenobiótico (JIANG et al. 2016; SCOW; HICKS, 2005).

Segundo Boopathy, (2000), a biorremediação tem a vantagem de ser relativamente simples, ter baixo custo e resultar na eliminação permanente ou diminuição dos contaminantes de águas subterrâneas, solos, lagos, além de que o mecanismo biológico evita o risco associado aos resíduos sintéticos perigosos (produtos químicos), proporcionando maior segurança e menos perturbações ao meio ambiente.

\subsection{Fungos com potencial para biorremediação de metais pesados}

A maneira com que os fungos vão interagir com os metais pesados depende do tipo de metal, organismo e ambiente. Um exemplo é quando o metal pesado é transportado para o interior da célula e modifica seu metabolismo (ROSS, 1975). Em outros casos os metais pesados podem bloquear grupos funcionais de enzimas celulares (ANAHID; YAGHMAEI; GHOBADINEJAD, 2011). Porém, algumas espécies conseguem se tornar resistentes a esses estresses.

Os fungos são descritos como excelentes agentes para biorremediação de solo e água, pois apresentam alta capacidade metabólica que pode ser aplicada aos metais pesados como o urânio. A capacidade metabólica faz com que os fungos tenham a possibilidade de sobreviver aos ambientes ácidos e contaminados com urânio (HÖLKER; FAKOUSSA; HÖFER, 1995; PAOLETTI, 1999; PEINTNER; MOSER, 1996).

Os fungos apresentam alto potencial para a biorremediação, uma vez que possuem a capacidade de acumular e imobilizar, em altas concentrações, uma variedade de metais pesados como Cu, Zn, Fe, U, Ni, Cd e Hg (BISHNOI; GARIMA, 2005; GADD, 1986).

A superfície celular fúngica apresenta quitina e quitosana, que são considerados excelentes sequestradores de íons de metais pesados (DAS; VIMALA; KARTHIKA, 2008). Os gêneros Penicillium spp., Aspergillus spp., Rhizopus spp., Mucor spp., Saccharomyces spp. e Fusarium spp. se mostraram excelentes bioadsorventes de íons de metais pesados (SHENO MERRIN et al. 1998; VOLESKY; MAY; HOLAN, 1993). 
Penicillium spp., Rhizopus spp. e Saccharomyces spp. podem bioadsorver metais pesados U, Th, Sr, Ni, Zn, Pb, Cr, As (GALUN et al. 1983; TAN; CHENG, 2003; TSEZOS; GEORGOUSIS; REMOUDAKI, 1997).

Os estudos sobre biorremediação de urânio têm focado nos mecanismos de biossorção do metal pela biomassa fúngica, entretanto estudos recentes indicam que os fungos podem apresentar outras maneiras de biorremediar esses metais pesados do ambiente (LIANG; GADD, 2017; QIAN et al. 2017; VÁZQUEZ-CAMPOS et al. 2015).

Existem 4 tipos principais de biorremediação utilizando fungos, que são: Biossorção, biomineralização, biorredução e bioacumulação (AYANGBENRO; BABALOLA, 2017).

A biossorção é um processo físico-químico onde ocorre a remoção de compostos da solução por organismos vivos ou mortos e seus derivados (MUSTAPHA; HALIMOON, 2015). Na biossorção de urânio ocorre a ligação físico-química do urânio com a biomassa fúngica, a biossorção inclui os mecanismos de adsorção e absorção, ou seja, após o processo o metal pode ser encontrado na porção interna ou externa da célula (GADD; FOMINA, 2011).

É importante salientar que nem todas as biomassas de microrganismos apresentam tais capacidades de biossorção, sendo indicado a realização de um "screening" para selecionar os fungos com melhor potencial (KOTA et al. 2014; OLSTORPE; SCHNÃRER; PASSOTH, 2009; TSEZOS; VOLESKY, 1982).

A biomineralização é o estudo dos processos sobre a interação entre estruturas orgânica-inorgânica mediada por microrganismos vivos. Por décadas surgiu a necessidade de serem identificadas moléculas envolvidas nesse processo e a interação entre elas (CRICHTON, 2012).

Em estudos com fungos do gênero Aspergillus, Liang et al. (2015), utilizando uma fonte de fosfato orgânico (glicerol 2-fosfato), observou que esses microrganismos foram capazes de liberar fosfato inorgânico no meio e assim precipitar o urânio em solução durante o crescimento.

Na biorredução, em ambientes onde o oxigênio $\left(\mathrm{O}_{2}\right)$ é escasso, algumas espécies fúngicas facultativas são capazes de utilizar receptores de elétrons diferentes do $\mathrm{O}_{2}$, como por exemplo os nitratos, neste caso acredita-se que o urânio solúvel (VI) pode ser utilizado como um receptor de elétrons alternativo e assim ser transformado em sua forma insolúvel U(IV) (GADD; FOMINA, 2011; NEWSOME; MORRIS; LLOYD, 2014). Os fungos 
podem também secretar uma alta quantidade de proteínas e outras enzimas que irão auxiliar os processos de biorredução (LLOYD, 2003).

Lovley \& Phillips, (1992) utilizaram vários potenciais inibidores (ânions e metais) da biorredução de urânio, somente altas concentrações de cobre inibiram a redução de urânio. Espécies de Aspergillus vêm sendo descritas como excelentes redutoras de metais (ABD EL HAMEED et al. 2015).

No processo de bioacumulação os fungos podem acumular urânio dentro de suas estruturas celulares, por vias de "bioacumulação" (DUPRÉ DE BOULOIS et al. 2008), a hipótese é que a captação pode ocorrer porque o transporte do metal é similar ao de nutrientes essenciais ao funcionamento da célula, como o urânio não tem funções biológicas conhecidas, acredita-se que a sua captação ocorre devido à mudança na permeabilidade da membrana celular, que acontece justamente por conta da sua toxicidade, o urânio é então armazenado no interior da célula em forma de grânulos de fosfato (NEWSOME; MORRIS; LLOYD, 2014).

A utilização de pó de rocha de fosfato, utilizado na agricultura como alternativa aos fertilizantes, pode ser um problema para muitos países em desenvolvimento, esse material pode conter altas concentrações de urânio, um exemplo é a área urano-fosfática existente no nordeste do Brasil, que compreende toda costa do estado de Pernambuco até a Paraíba (150 km de extensão) onde a concentração natural de urânio é de 150 a 200 ppm (MORAES et al. 2013). Algumas espécies fúngicas podem competir com plantas nesses ambientes e acumular urânio, isso é importante, pois a simbiose reduz o acúmulo do metal nos vegetais, os quais podem posteriormente ser consumidos por animais e humanos (DUPRÉ DE BOULOIS et al. 2008).

A realização da biorremediação de locais contaminados com a utilização de fungos, apresenta algumas vantagens sobre as bactérias, uma vez que são capazes de adsorver, acumular e imobilizar metais tóxicos sofrendo pouca ou nenhuma ação tóxica, principalmente devido a sua alta capacidade metabólica (DAVIS et al. 1993).

A maioria dos estudos em relação à captação de urânio por biomassa fúngica tem se concentrado em mecanismos de absorção e adsorção (ALI; HASHEM, 2007; GALUN et al. 1983; VÁZQUEZ-CAMPOS et al. 2015).

A remoção de metais pesados precisa ser feita o quanto antes, já que quanto maior o tempo dos poluentes no ambiente mais difícil pode ser a sua remediação (D’ANNIBALE et al. 2005,2006). 
A área onde funcionava a mina encontra-se fechada para o acesso público devido aos riscos de contaminação, apenas pesquisadores e funcionários do IPEN e CNEN têm acesso ao local. 


\section{CONCLUSÕES}

-A caracterização química das amostras de água revelou pH ácido (média de 3,3) concentrações de urânio até 200 vezes acima dos limites estabelecidos pela Legislação Brasileira $(0,02 \mathrm{mg} / \mathrm{Kg})$;

-Os resultados da caracterização química das amostras de solo e sedimento revelaram altas concentrações de urânio, porém não existem limites estabelecidos pela Legislação Brasileira;

-Os resultados da caracterização química das amostras de água, solo e sedimento revelaram os efeitos prejudiciais causados pela drenagem ácida de mina;

-Apesar de apresentarem as maiores concentrações de urânio, foram das amostras de solo e sedimento que a maioria dos fungos filamentosos foram isolados;

-Foram isolados e identificados 57 fungos, destacando-se o gênero Penicillim como o mais frequentes. Dentro do gênero, a espécie Penicillium piscarium foi a mais prevalente;

-Dos 57 isolados fúngicos, 38\% (22) foram tolerantes ao urânio. Desses fungos, 14 foram isolados das amostras de solo, onde as espécies de Penicillium citrinum foram as mais tolerantes;

-O aumento das concentrações de urânio no meio reduziu a velocidade de crescimento micelial (IVCM) dos fungos isolados;

-Em relação a Concentração Inibitória Mínima (CIM), 56 (98\%) fungos cresceram na concentração de 1000 mg/L. Vinte e cinco fungos (44\%) não tiveram a CIM definida, pois cresceram nas maiores concentrações de urânio empregadas (8000 mg/L), demonstrando que os fungos isolados da mina Osamu Utsumi apresentam alta resistência ao urânio;

-Os testes de biossorção de urânio do meio aquoso, utilizando biomassa viva dos fungos, demonstraram que 11 espécies fúngicas apresentaram alto potencial para biorremediação do metal, destacando-se as espécies de Penicillium piscarium; Gongronella butleri; Phoma nebulosa e Talaromyces amestolkiae.

-A comparação entre os resultados de biossorção e tolerância/resistência sugere uma baixa relação entre resistência ao urânio e capacidade de biossorção. Portanto, o acumulo de urânio pelos fungos, de forma geral, nem sempre está relacionado com a maior tolerância/resistência ao metal pesado. 
-Dentre os 57 isolados fúngicos, 5 espécies se destacaram por apresentarem alta resistência ao urânio e ótimo potencial para remoção de urânio do meio aquoso, a saber: Gongronella butleri, Penicillium piscarium, Penicillium citrinum, Penicillium ludwigii, Talaromyces amestolkiae. Portanto, esses fungos podem ser importantes como alternativa para os processos convencionais no tratamento de ambientes contaminados com urânio. 


\section{REFERÊNCIAS}

ABD EL HAMEED, A. H. et al. Biosorption of uranium and heavy metals using some local fungi isolated from phosphatic fertilizers. Annals of Agricultural Sciences, v. 60 , n. 2 , p. $345-351,1$ dez. 2015.

ABDOLLAHI, A.; BUCHANAN, R. L. Regulation of Aflatoxin Biosynthesis: Characterization of Glucose as an Apparent Inducer of Aflatoxin Production. Journal of Food Science, v. 46, n. 1, p. 143-146, jan. 1981.

AGI. What are regulations mining activities. 2018. American Geoc. Institute. Disponível em: <https://www.americangeosciences.org/critical-issues/faq/what-areregulations-mining-activities>. Acesso em: 1 jan. 2019.

AHMAD, I.; ZAFAR, S.; AHMAD, F. Heavy Metal Biosorption potential of Aspergillus and Rhizopus sp . isolated from Wastewater treated soil. Journal of applied science and environmental management, v. 9, n. 1, p. 123-126, 2005.

AKHTAR, S. et al. Metal tolerance potential of filamentous fungi isolated from soils irrigated with untreated municipal effluent. soil Environ., v. 32, n. 1, p. 55-62, 2013.

ALI, E. H.; HASHEM, M. Removal Efficiency of the Heavy Metals Zn(II), Pb(II) and Cd(II) by Saprolegnia delica and Trichoderma viride at Different $\mathrm{pH}$ Values and Temperature Degrees. Mycobiology, v. 35, n. 3, p. 135-44, 2007.

ALTSCHUL, S. F. et al. Basic local alignment search tool. Journal of molecular biology, v. 215, n. 3, p. 403-10, 5 out. 1990.

ANAHID, S.; YAGHMAEI, S.; GHOBADINEJAD, Z. Heavy metal tolerance of fungi. Scientia Iranica, v. 18, n. 3 C, p. 502-508, 2011.

ANDERSEN, B. et al. Associations between fungal species and water-damaged building materials. Applied and Environmental Microbiology, v. 77, n. 12, p. 41804188, 2011.

ARX, J. . VON. The genera of fungi sporulating in pure culture. 2. ed. [s.1.] Cramer, Vaduz, 1974.

ASSUNÇÃO, E. et al. Effects of Gamma and Electron Beam Radiation on Brazil Nuts Artificially Inoculated with Aspergillus flavus. Journal of food protection, v. 78, n. 7, p. 1397-401, 2015.

ATSDR. Public Health Statement for Uranium. In: Toxicological Profile for Uranium. Atlanta, 2019. Disponível em: <https://www.atsdr.cdc.gov/toxprofiles/tp150- 
c1.pdf>. Acesso em: 8 fev. 2019.

AYANGBENRO, A. S.; BABALOLA, O. O. A New Strategy for Heavy Metal Polluted Environments: A Review of Microbial Biosorbents. International journal of environmental research and public health, v. 14, n. 1, 2017.

AZUBUIKE, C. C.; CHIKERE, C. B.; OKPOKWASILI, G. C. Bioremediation techniques-classification based on site of application: principles, advantages, limitations and prospects. World Journal of Microbiology and Biotechnology, v. 32, n. 11, p. 1$18,2016$.

BABIČ, M. N. et al. Fungal contaminants in drinking water regulation? A tale of ecology, exposure, purification and clinical relevance. International Journal of Environmental Research and Public Health, v. 14, n. 6, p. 636, 13 jun. 2017.

BAHOBIL, A. et al. Fungal Biosorption for Cadmium and Mercury Heavy Metal Ions Isolated from Some Polluted Localities in KSA. Int.J.Curr.Microbiol.App.Sci, v. 6, n. 6, p. 2138-2154, 2017.

BAKER, B. J. et al. Metabolically active eukaryotic communities in extremely acidic mine drainage. Applied and Environmental Microbiology, v. 70, n. 10, p. 62646271, 1 out. 2004.

BALDRIAN, P. Interactions of heavy metals with white-rot fungi. Enzyme and Microbial Technology, v. 32, n. 1, p. 78-91, 2003.

BAN, Y. et al. The Response of Dark Septate Endophytes (DSE) to Heavy Metals in Pure Culture. PLoS ONE, v. 7, n. 10, 2012.

BANNING, A. et al. Drinking Water Uranium and Potential Health Effects in the German Federal State of Bavaria. International Journal of Environmental Research and Public Health, v. 14, n. 8, p. 927, 18 ago. 2017.

BAQUIÃO, A. C. et al. Mycoflora and mycotoxins in field samples of Brazil nuts. Food Control, v. 28, n. 2, p. 224-229, 1 dez. 2012.

BARRON, G. L. The genera of Hyphomycetes from soil. New York: R.E. Krieger, 1972.

BARROS JÚNIOR, L. M. et al. Biosorption of cadmium using the fungus Aspergillus niger. Brazilian Journal of Chemical Engineering, v. 20, n. 3, p. 229-239, set. 2003 .

BARROW, J. R.; AALTONEN, R. E. Evaluation of the internal colonization of atriplex canescens (pursh) nutt. roots by dark septate fungi and the influence of host physiological activity. Mycorrhiza, v. 11, n. 4, p. 199-205, 2001. 
BENGTSSON, L. et al. Studies on the biosorption of uranium by Talaromyces emersonii CBS 814.70 biomass. Applied Microbiology and Biotechnology, v. 42, n. 5, p. 807-811, jan. 1995.

BHAT, U. N.; KHAN, A. B. Heavy Metals: An Ambiguous Category of Inorganic Contaminants, Nutrients and Toxins. Research Journal of Environmental Sciences, v. 5, n. 8, p. 682-690, 1 ago. 2011.

BISHNOI, N. R.; GARIMA, A. Fungus - An alternative for bioremediation of heavy metal containing wastewater: A review. Journal of Scientific and Industrial Research, v. 64, n. 2, p. 93-100, 2005.

BOOPATHY, R. Factors limiting bioremediation technologies. Bioresource Technology, v. 74, n. 1, p. 63-67, 2000.

BOZZOLA, J. J.; RUSSELL, L. D. Electron Microscopy. 2. ed. Boston: ones \& Bartlett Publishers, 1998.

BUTTERWORTH, A. The Significance and Value of Uranium in Urine Analysis. Trans. Assoc. Ind. Med, v. 5, n. 3, p. 36-46, 1955.

CAPPELLO, F.; MACARIO, A. J. L. Depleted uranium induces human carcinogenesis involving the immune and chaperoning systems: Realities and working hypotheses. Medical Hypotheses, v. 124, p. 26-30, mar. 2019.

CCME. Canadian Council of Ministers of the Environment. Canadian Soil Quality Guidelines for the Protection of Environmental and Human Health, uranium. 2007. Book: Canadian environmental quality guidelines.14 pages.

CHAN, W. K. et al. Mycoremediation of Heavy Metal/Metalloid-Contaminated Soil: Current Understanding and Future Prospects. In: [s.1.] Springer, Cham, 2016. p. 249-272.

CHÁVEZ, R. et al. Filamentous fungi from extreme environments as a promising source of novel bioactive secondary metabolites. Frontiers in microbiology, v. 6, p. 903, 2015.

CHENG, S. et al. Efficiency of constructed wetlands in decontamination of water polluted by heavy metals. Ecological Engineering, v. 18, n. 3, p. 317-325, 1 jan. 2002.

CIPRIANI, M. Mitigação dos impactos sociais e ambientais decorrentes do fechamento definitivo de minas de urânio. 2002. 332 p. Tese (Doutorado em Geociências) - Instituto de Geociências, Universidade Estadual de Campinas, Campinas, 2002.

CLESCERI, L. S. Standard Methods for the Examination of Water and Wastewater. [s.1.] American Public Health Association, 1998. 
CNEN. Avaliação da qualidade das águas e sedimentos das microbacias do ribeirão das antas e do ribeirão de caldas no planalto de poços de caldas. Relatório técnico da comissão das águas. CNEN, 52 p. Poços de Caldas, 2012.

COLLINS, Y.; STOTZKY, G. Factors affecting the toxicity of heavy metals to microbes. In: DOYLE, T. J.; BEVERIDGE, R. J. (Eds.). . Metal ions and Bacteria. Toronto: Wiley, p. 31-90, 1989.

CRICHTON, R. R.; CRICHTON, R. R. Biomineralisation. Biological Inorganic Chemistry, p. 359-378, 1 jan. 2012.

CUMBERLAND, S. A. et al. Uranium mobility in organic matter-rich sediments: A review of geological and geochemical processes. Earth-Science Reviews, v. 159, p. 160-185, 1 ago. 2016.

D’ANNIBALE, A. et al. Degradation of aromatic hydrocarbons by white-rot fungi in a historically contaminated soil. Biotechnology and Bioengineering, v. 90, n. 6, p. 723-731, 20 jun. 2005.

D'ANNIBALE, A. et al. Role of Autochthonous Filamentous Fungi in Bioremediation of a Soil Historically Contaminated with Aromatic Hydrocarbons. Applied and Environmental Microbiology, v. 72, n. 1, p. 28-36, 3 jan. 2006.

DAS, N.; VIMALA, R.; KARTHIKA, P. Biosorption of heavy metals - An overview. Indian Journal of Biotechnology, v. 7, n. 2, p. 159-169, 2008.

DAVIS, M. W. et al. Field evaluation of the lignin-degrading fungus Phanerochaete sordida to treat creosote-contaminated soil. Environmental Science \& Technology, v. 27, n. 12, p. 2572-2576, nov. 1993.

DEGOLA, F. et al. A multiplex RT-PCR approach to detect aflatoxigenic strains of Aspergillus flavus. Journal of applied microbiology, v. 103, n. 2, p. 409-17, ago. 2007.

DEL, B. et al. Diversity and Distribution of Heavy Metal-Resistant Bacteria in Polluted Sediments of the Araça Bay, São Sebastião ( SP ), and the Relationship Between Heavy Metals and Organic Matter Concentrations. Microbial Ecology, 2016.

DHAR, R. et al. Yeast adapts to a changing stressful environment by evolving cross-protection and anticipatory gene regulation. Molecular Biology and Evolution, v. 30, n. 3, p. 573-588, 2013.

DIAS, M. D. et al. Efeito da temperatura no crescimento micelial , produção e germinação de conídios de Colletotrichum spp . isolados de Coffea arabica L. Ciênc. agrotec., v. 29, n. 3, p. 545-552, 2005.

DUFFUS, J. H. "Heavy metals" a meaningless term? (IUPAC Technical Report). 
Pure and Applied Chemistry, v. 74, n. 5, p. 793-807, 2002.

DUPRÉ DE BOULOIS, H. et al. Impact of arbuscular mycorrhizal fungi on uranium accumulation by plants. Journal of Environmental Radioactivity, v. 99, n. 5, p. 775-784, 1 maio 2008.

DUTRA, P. H. et al. Impact of 210pb from Osamu Utsumi mine on sediment of rivers in caldas region, Minas Gerais. 2013 International Nuclear Atlantic Conference - INAC 2013, v. 45, n. 32, p. 10, 2013.

DZIONEK, A.; WOJCIESZYŃSKA, D.; GUZIK, U. Natural carriers in bioremediation: A review. Electronic Journal of Biotechnology, v. 23, p. 28-36, 1 set. 2016.

ELBAZ-POULICHET, F. et al. Trace metal and nutrient distribution in an extremely low pH (2.5) river-estuarine system, the Ria of Huelva (South-West Spain). Science of The Total Environment, v. 227, n. 1, p. 73-83, fev. 1999.

ELDERFIELD, H.; UPSTILL-GODDARD, R.; SHOLKOVITZ, E. R. The rare earth elements in rivers, estuaries, and coastal seas and their significance to the composition of ocean waters. Geochimica et Cosmochimica Acta, v. 54, n. 4, p. 971991, abr. 1990.

ELLESS, M. P.; LEE, S. Y. Uranium Solubility of Carbonate-Rich UraniumContaminated Soils. Water, Air, and Soil Pollution, v. 107, n. 1/4, p. 147-162, 1998.

EPA. Introduction to in Situ Bioremediation of Groundwater. p. 1-86, 2013.

EZZOUHRI, L. et al. Heavy metal tolerance of filamentous fungi isolated from polluted sites in Tangier, African Journ. of Microbiology. Morocco. v. 3, n. 2, p. 3548, 2009.

FAGUNDES, J. R. T. Balanço hídrico do bota-fora bf4 da mina osamu otsumi, inb, como Subsídio para Projetos de Remediação de Drenagem Ácida. Revista Brasileira de recursos hidricos, v. 13, n. 1, p. 19-28, 2008.

FARHAN, S. N.; KHADOM, A. A. Biosorption of heavy metals from aqueous solutions by Saccharomyces Cerevisiae. International Journal of Industrial Chemistry, v. 6, n. 2, p. 119-130, 18 jun. 2015.

FAZLI, M. M. et al. Highly cadmium tolerant fungi: their tolerance and removal potential. Journal of environmental health science \& engineering, v. 13, n. July, p. 19, 2015.

FERRARI, C. R. Avaliação de efeitos ambientais de efluentes radioativos de mineração de urânio sobre as características físicas, químicas e diversidade da 
Comunidade Zooplanctônica na Unidade de Tratamento de Minérios, Represa das Antas e Represa Bortolan, Poços de Caldas. 2010. 132p. Dissertação (Mestrado em Biotecnologia), Instituto de Ciências Biomédicas, Universidade de São Paulo, São Paulo, 2010 .

FERRARI, C. R. et al. Effects of the discharge of uranium mining effluents on the water quality of the reservoir: An integrative chemical and ecotoxicological assessment. Scientific Reports, v. 7, n. 1, 2017.

FERREIRA, V. et al. Contamination by uranium mine drainages affects fungal growth and interactions between fungal species and strains. Mycologia, v. 102, n. 5, p. 1004-1011, 2010.

FETTUS, G. H.; MCKINZIE, M. G. Nuclear Fuel's Dirty Beginnings: Environmental Damage and Public Health Risks From Uranium Mining in the American West. 2002. Disponível em: <https://www.nrdc.org/sites/default/files/uranium-miningreport.pdf>. Acesso em: 7 fev. 2019.

FPTCD, F. P. T. C. ON D. Uranium in Drinking Water. 2017 Disponível em: $<$ https://www.canada.ca/content/dam/hc-sc/documents/programs/consultation-uraniumdrinking-water/consultation-uranium-drinking-water-eng.pdf>. Acesso em: 14 fev. 2019.

GAD, A. S. The Potential Impact of Micro-organisms on Radioactive Wastes. Chemistry Research Journal, v. 2017, n. 6, p. 1-7, 2017.

GADD, G. M. The uptake of heavy metals by fungi and yeasts: the chemistry and physiology of the process and applications for biotechnology. In: ECCLES, H. H.; HUNT, S. (Eds.). . Immobilisation of lons by Bio-sorption. [s.1.] Ellis Horwood, Chichester, 1986. p. 135-147.

GADD, G. M. et al. Nutritional influence on fungal colony growth and biomass distribution in response to toxic metals. FEMS Microbiology Letters, v. 204, n. 2, p. 311-316, 1 nov. 2001.

GADD, G. M.; FOMINA, M. Uranium and Fungi. Geomicrobiology Journal, v. 28, p. 471-482, 2011.

GADD, G. M.; GRIFFITHS, A. J. Effect of copper on morphology of Aureobasidium pullulans. Transactions of the British Mycological Society, v. 74, n. 2, p. 387-392, 1 abr. 1980.

GALUN, M. et al. Recovery of uranium (VI) from solution using fungi II. Release from uranium-loaded Penicillium biomass. Water, Air, and Soil Pollution, v. 20, n. 3, out. 1983. 
GARBISU, C.; ALKORTA, I. Basic concepts on heavy metal soil bioremediation. European Journal of Mineral Processing and Environmental Protection, v. 3, n. 1, p. 58-66, 2003.

GOMES, A. F. DA S.; LADEIRA, A. C. Q. Caracterização de lamas contendo urânio como subsídio para ações futuras de mitigação. Rem: Revista Escola de Minas, v. 64 , n. 4, p. 479-485, dez. 2011.

GOMES, N. C. M.; MENDONCA-HAGLER, L. C. S.; SAVVAIDIS, I. Metal Bioremediation by Microorganisms. Revista de microbiologia, v. 29, n. 2, p. 85-92, 1998.

GOMPERTZ, O. F. et al. Estrutura, morfologia, reprodução e taxonomia dos fungos. Microbiologia, p. 888, 2015.

GRÄFE, M.; KLAUBER, C. Bauxite residue issues: IV. Old obstacles and new pathways for in situ residue bioremediation. Hydrometallurgy, v. 108, p. 46-59, 2011.

GRUHN, C. M.; MILLER, O. K. Effect of copper on tyrosinase activity and polyamine content of some ectomycorrhizal fungi. Mycological Research, v. 95, n. 3, p. 268-272, 1991.

GUÉGUEN, Y. et al. Short-term hepatic effects of depleted uranium on xenobiotic and bile acid metabolizing cytochrome P450 enzymes in the rat. Archives of Toxicology, v. 80, n. 4, p. 187-195, 18 abr. 2006.

GUIBAL, E.; ROULPH, C.; LE CLOIREC, P. Uranium biosorption by a filamentous fungus Mucor miehei $\mathrm{pH}$ effect on mechanisms and performances of uptake. Water Research, v. 26, n. 8, p. 1139-1145, 1 ago. 1992.

HAMDI, H. et al. Bioaugmentation and biostimulation effects on PAH dissipation and soil ecotoxicity under controlled conditions. Soil Biology and Biochemistry, v. 39, n. 8, p. 1926-1935, 2007.

HARDER, J. What if you ate uranium?. 2019. Disponível em: $<$ https://science.howstuffworks.com/science-vs-myth/what-if/what-if-ateuranium.htm>. Acesso em: 7 fev. 2019.

HÖLKER, U.; FAKOUSSA, R. M.; HÖFER, M. Growth substrates control the ability of Fusarium oxysporum to solubilize low-rank coal. Applied Microbiology and Biotechnology, v. 44, n. 3-4, p. 351-355, dez. 1995.

HU, K.-J. et al. Screening of fungi for chitosan producers, and copper adsorption capacity of fungal chitosan and chitosanaceous materials. Carbohydrate Polymers, v. 58, n. 1, p. 45-52, 1 out. 2004. 
IBRAM. Impactos da mineração na economia brasileira. Instituto Brasileiro de Mineração. 2015. Disponível em: <http://www.ibram.org.br/>. Acesso em: 10 jan. 2019.

JÄRUP, L. Hazards of heavy metal contamination. British Medical Bulletin, v. 68, p. 167-182, 2003.

JIANG, Y. et al. Insights into the biodegradation of weathered hydrocarbons in contaminated soils by bioaugmentation and nutrient stimulation. Chemosphere, v. 161, p. 300-307, 1 out. 2016.

JO, W. S. et al. Culture Conditions for the Mycelial Growth of Ganoderma applanatum. Mycobiology, v. 37, n. 2, p. 94-102, jun. 2009.

KAR, A.; SHETTY, R.; HEGDE, A. M. Enamel defects seen among children residing near uranium mines. A case control study. IOSR Journal of Dental and Medical Sciences (IOSR-JDMS) e-ISSN, v. 15, n. 1, p. 137-142, 2016.

KATAR, Ş. et al. Talaromyces aculeatus from acidic environment as a new fungal biosorbent for removal of some reactive textile dyes. Anadolu University Journal of Science and Technology A-Applied Sciences and Engineering, 2017.

KOTA, M. F. et al. Bioremediation of crude oil by different fungal genera. Asian Journal of Plant Biology. v. 2, n. 1, p. 11-18, 2014.

KOZAKIEWICZ, Z. Aspergillus species on the stored products. Mycological Papers, v. 161, p. 188, 1989.

KURTTIO, P. et al. Renal effects of uranium in drinking water. Environmental health perspectives, v. 110, n. 4, p. 337-42, abr. 2002.

LADEIRA, A. C. Q.; GONÇALVES, C. R. Influence of anionic species on uranium separation from acid mine water using strong base resins. Journal of hazardous materials, v. 148, n. 3, p. 499-504, 30 set. 2007.

LEITÃO, A. L. Potential of Penicillium species in the bioremediation field. International Journal of Environmental Research and Public Health, v. 6, n. 4, p. 1393-1417, 2009.

LI, M. et al. Combined Application of Rice Straw and Fungus Penicillium Chrysogenum to Remediate Heavy-Metal-Contaminated Soil. Soil and Sediment Contamination: An International Journal, v. 23, n. 3, p. 328-338, 29 jan. 2014.

LIANG, X. et al. Uranium phosphate biomineralization by fungi. Environmental Microbiology, v. 17, n. 6, p. 2064-2075, 2015.

LIANG, X.; GADD, G. M. Metal and metalloid biorecovery using fungi. Microbial biotechnology, v. 10, n. 5, p. 1199-1205, 2017. 
LIMA, H. M. DE; FLORES, J. C. DO C.; COSTA, F. L. Plano de recuperação de áreas degradadas versus plano de fechamento de mina: um estudo comparativo. Rem: Revista Escola de Minas, v. 59, n. 4, p. 397-402, dez. 2006.

LIU, R. et al. Effect of $\mathrm{pH}$ on biosorption of boron onto cotton cellulose. Desalination, v. 207, n. 1-3, p. 257-267, 10 mar. 2007.

LLOYD, J. R. Microbial reduction of metals and radionuclides. FEMS Microbiology Reviews, v. 27, n. 2-3, p. 411-425, 1 jun. 2003.

LÓPEZ-ARCHILLA, A. I. et al. Ecological study of the fungal populations of the acidic Tinto River in southwestern Spain. Canadian Journal of Microbiology, v. 50, n. 11, p. 923-934, nov. 2004.

LOVLEY, D. R.; PHILLIPS, E. J. P. Bioremediation of uranium contamination with enzymatic uranium reduction. Environmental Science \& Technology, v. 26, n. 11, p. 2228-2234, nov. 1992.

LYEW, D.; SHEPPARD, J. D. Effects of physical parameters of a gravel bed on the activity of sulphate-reducing bacteria in the presence of acid mine drainage. Journal of Chemical Technology \& Biotechnology, v. 70, n. 3, p. 223-230, nov. 1997.

MAGAN, N. Fungi in Extreme Environments. In: KUBICEK, C.; DRUZHININA, I. (Eds.). . Environmental and Microbial Relationships. 4. ed. Berlin, Heidelberg: Springer Berlin Heidelberg, 2007. p. 85-103.

MAJUMDER, E. L.-W.; WALL, J. D. Uranium Bio-Transformations: Chemical or Biological Processes? Open Journal of Inorganic Chemistry, v. 07, n. 02, p. 28-60, 7 abr. 2017..

MARIA, A.; ANDRADE, R. DE. Átomos na política internacional Atoms in international politics. Revista CTS, no , v. 7, p. 113-140, 2012.

MARTINS, C. M. et al. Estudo microbiológico relacionado à geração de drenagem ácida em antigas minas de pirita no município de ouro preto, mg. Geochim. Brasil., 18(2)077-085, 2004.

MAYNARD, E.; HODGE, H. Studies of the toxicity of various uranium compounds when fed to experimental animals. In: HODGE, H. (Ed.). Pharmacology and Toxicology of Uranium Compounds. New York: [s.n.]. p. 309-376.

MEINRATH, A.; SCHNEIDER, P.; MEINRATH, G. Uranium ores and depleted uranium in the environment, with a reference to uranium in the biosphere from the Erzgebirge/Sachsen, Germany. Journal of Environmental Radioactivity, v. 64, n. 2-3, p. 175-193, 1 jan. 2003. 
MORAES, E. N. et al. Radiometria em área urano-fosfática da cidade de igarassupernambuco. IX Latin American IRPA Regional Congress on Radiation Protection and Safety - IRPA. Rio de Janeiro. 2013. Disponível em: $<$ https://inis.iaea.org/collection/NCLCollectionStore/_Public/45/071/45071075.pdf>. Acesso em: 12 fev. 2019.

MUMTAZ, S. et al. Fungi outcompete bacteria under increased uranium concentration in culture media. Journal of Environmental Radioactivity, v. 120, p. 3944, 2013.

MUSTAPHA, M. U.; HALIMOON, N. Microorganisms and Biosorption of Heavy Metals in the Environment: A Review Paper. Journal of Microbial \& Biochemical Technology, v. 07, n. 05, p. 1-4, 20 ago. 2015.

NASCIMENTO, M. R. L.; FATIBELLO-FILHO, O.; TEIXEIRA, L. A. Recovery of uranium from acid mine drainage wasters by ion exchange. Mineral Processing and Extractive Metallurgy Review, v. 25, n. 2, p. 129-142, 12 abr. 2004.

NAVRATIL, J. D. Advances in treatment methods for uranium contaminated soil and water. Archive of Oncology, v. 9, n. 4, p. 257-260, 2001.

NRC. Uranium Mining in Virginia: Scientific, Technical, Environmental, Human Health and Safety, and Regulatory Aspects of Uranium Mining and Processing in Virginia. National Research Council. Washington, DC: The National Academies Press. 360p. 2012.

NEVES, O.; ABREU, M. M. Are uranium-contaminated soil and irrigation water a risk for human vegetables consumers? A study case with Solanum tuberosum L., Phaseolus vulgaris L. and Lactuca sativa L. Ecotoxicology, v. 18, n. 8, p. 1130-1136, 10 nov. 2009.

NEWBY, P. J.; GADD, G. M. Synnema induction in Penicillium funiculosum by tributyltin compounds. Transactions of the British Mycological Society, v. 89, n. 3, p. 381-384, 1 out. 1987.

NEWSOME, L.; MORRIS, K.; LLOYD, J. R. The biogeochemistry and bioremediation of uranium and other priority radionuclides. Chemical Geology, v. 363, p. 164-184, 10 jan. 2014.

NIES, D. H. Microbial heavy-metal resistance. Applied microbiology and biotechnology, v. 51, n. 6, p. 730-50, jun. 1999.

NÓBREGA, F. A.; LIMA, H. M. DE; LEITE, A. DO L. Análise de múltiplas variáveis no fechamento de mina: estudo de caso da pilha de estéril BF-4, Mina Osamu 
Utsumi, INB Caldas, Minas Gerais. Rem: Revista Escola de Minas, v. 61, n. 2, p. 197202, jun. 2008.

OGAR, A. et al. ScienceDirect Stabilization of Uranium(VI) at Low pH by Fungal Metabolites: Applications in Environmental Biotechnology. APCBEE Procedia, v. 10, n. Vi, p. 142-148., 2014.

OHJI, T. Advances in materials science for environmental and energy technologies. Wiley, American Ceramic Society, vol. 241, New Jersey, 2012.

OLSTORPE, M.; SCHNÃRER, J.; PASSOTH, V. Screening of yeast strains for phytase activity. FEMS Yeast Research, v. 9, n. 3, p. 478-488, 1 maio 2009.

OLSZEWSKI, G.; BORYŁO, A.; SKWARZEC, B. Uranium (234U, 235U and $238 \mathrm{U}$ ) contamination of the environment surrounding phosphogypsum waste heap in Wiślinka (northern Poland). Journal of Environmental Radioactivity, v. 146, p. 56-66, 1 ago. 2015.

PAN, R.; CAO, L.; ZHANG, R. Combined effects of $\mathrm{Cu}, \mathrm{Cd}, \mathrm{Pb}$, and $\mathrm{Zn}$ on the growth and uptake of consortium of Cu-resistant Penicillium sp. A1 and Cd-resistant Fusarium sp. A19. Journal of Hazardous Materials, v. 171, n. 1-3, p. 761-766, 2009.

PANG, C. et al. Biosorption of uranium(VI) from aqueous solution by dead fungal biomass of Penicillium citrinum. Chemical Engineering Journal, v. 170, n. 1, p. 1-6, 2011.

PANNU, T. S.; SUKHMANI; GILL, K. S. Uranium-Toxicity and UraniumInduced Osteosarcoma Using A New Regimen and Surgery : A First-Time Experience. Journal of clinical and diagnostic research : JCDR, v. 9, n. 6, p. RD01-3, jun. 2015.

PAOLETTI, M. G. Using bioindicators based on biodiversity to assess landscape sustainability. Agriculture, Ecosystems \& Environment, v. 74, n. 1-3, p. 1-18, jun. 1999.

PATEL, R.; CHANDEL, M. Effect of $\mathrm{pH}$ and Temperature on the Biosorption of Heavy Metals by Bacillus licheniformis. International Journal of Science and Research (IJSR) ISSN. Vol 4 (1), 2272-2275, jan. 2015.

PEDROBOM, J. H. et al. In situ speciation of uranium in treated acid mine drainage using the diffusion gradients in thin films technique (DGT). Chemosphere, v. 169, p. 249-256, 1 fev. 2017.

PEINTNER, U.; MOSER, M. Survey of heavy metal deposition at the Schulterberg (Achenkirch altitude profiles) by using basidiomycetes as bioindicators. Phyton Annales Rei Botanicae, v. 36, n. 4, p. 155-162, 1996. 
PIMENTEL-GOMES, F. Curso de Estatística Experimental. 15. ed. Piracicaba: Fealq, 2009.

PIMMATA, P.; REUNGSANG, A.; PLANGKLANG, P. Comparative bioremediation of carbofuran contaminated soil by natural attenuation, bioaugmentation and biostimulation. International Biodeterioration \& Biodegradation, v. 85, p. 196204, 2013.

PITT, J. I.; HOCKING, A. D. Fungi and Food Spoilage. New York: Springer US, 2009.

PITT, J. I.; HOCKING, A. D. Fungi and food spoilage (2nd ed.). London: Blackie Academic and Professional. 1997.

PLUMRIDGE, A. et al. The weak acid preservative sorbic acid inhibits conidial germination and mycelial growth of Aspergillus niger through intracellular acidification. Applied and environmental microbiology, v. 70, n. 6, p. 3506-11, jun. 2004.

POSTON, T. M.; HANF, R. W.; SIMMONS, M. A. Toxicity of uranium to Daphnia magna. Water, Air, and Soil Pollution, v. 22, n. 3, p. 289-298, abr. 1984.

QIAN, X. et al. Characterization of fungal-mediated carbonate precipitation in the biomineralization of chromate and lead from an aqueous solution and soil. Journal of Cleaner Production, v. 164, p. 198-208, 15 out. 2017.

RADESPIEL-TRÖGER, M.; MEYER, M. Association between drinking water uranium content and cancer risk in Bavaria, Germany. International Archives of Occupational and Environmental Health, v. 86, n. 7, p. 767-776, 6 out. 2013.

RAHMAN, K. S. M. et al. Bioremediation of gasoline contaminated soil by a bacterial consortium amended with poultry litter, coir pith and rhamnolipid biosurfactant. Bioresource technology, v. 81, n. 1, p. 25-32, jan. 2002.

RAMAKRISHNA, N.; LACEY, J.; SMITH, J. E. Effects of water activity and temperature on the growth of fungi interacting on barley grain. Mycological Research, v. 97, n. 11, p. 1393-1402, 1 nov. 1993.

RASKIN, I. et al. Bioconcentration of heavy metals by plants. Current Opinion in Biotechnology, v. 5, n. 3, p. 285-290, jun. 1994.

REISINGER, S. et al. Heavy metal tolerance and accumulation in Indian mustard (Brassica juncea L.) expressing bacterial gamma-glutamylcysteine synthetase or glutathione synthetase. International journal of phytoremediation, v. 10, p. 440-454, 2008.

RIDDEL, R. W. Permanent staired mycological preparations obtained by slide 
culture mycology. v. 42, 1950. p. 265-270

ROBERTS, D. Uranium Toxicity. Agency for Toxic Substances and Disease Registry Case Studies in Environmental Medicine (CSEM). 2012. Disponível em: <www.atsdr.cdc.gov/csem/>. Acesso em: 7 fev. 2019.

ROSS, I. S. Some effects of heavy metals on fungal cells. Transactions of the British Mycological Society, v. 64, n. 2, p. 175-193, 1 abr. 1975.

ROYCHOWDHURY, A.; SARKAR, D.; DATTA, R. Remediation of Acid Mine Drainage-Impacted Water. Current Pollution Reports, v. 1, n. 3, p. 131-141, 16 set. 2015.

RUFYIKIRI, G. et al. Arbuscular mycorrhizal fungi can decrease the uptake of uranium by subterranean clover grown at high levels of uranium in soil. Environmental Pollution, v. 130, n. 3, p. 427-436, 2004.

SAFDARI, M. S. et al. Development of bioreactors for comparative study of natural attenuation, biostimulation, and bioaugmentation of petroleum-hydrocarbon contaminated soil. Journal of Hazardous Materials, v. 342, p. 270-278, 15 jan. 2018.

SALVADORI, M. R. et al. Bioremediation from wastewater and extracellular synthesis of copper nanoparticles by the fungus Trichoderma koningiopsis. Journal of environmental science and health. Part A, Toxic/hazardous substances \& environmental engineering, v. 49, n. November, p. 1286-95, 2014.

SAMBROOK, J.; FRITSCH, E. F.; MANIATS, T. Molecular clonig: a laboratory manual. 2. ed. New York: Cold Spring Harbor: Cold Spring Harbor Laboratory, 1989.

SANA, S.; ROOSTAAZAD, R.; YAGHMAEI, S. Biosorption of Uranium (VI) from Aqueous Solution by Pretreated Aspergillus niger Using Sodium Hydroxide. Iranian Journal of Chemistry \& Chemical Engineering-International English Edition, v. 34, n. 1, p. 65-74, 2015.

SCOW, K. M.; HICKS, K. A. Natural attenuation and enhanced bioremediation of organic contaminants in groundwater. Current Opinion in Biotechnology, v. 16, n. 3, p. 246-253, 1 jun. 2005.

SELBMANN, L. et al. Drought meets acid: three new genera in a dothidealean clade of extremotolerant fungi. Studies in Mycology, v. 61, p. 1-20, 2008.

SHAZIA, I.; UZMA, G.; TALAT, A. Bioremediation of Heavy Metals Using Isolates of Filamentous Fungus Aspergillus fumigatus Collected from Polluted Soil of Kasur, Pakistan. International Research Journal of Biological Sciences, v. 2, n. 12, p. 66-73, 2013. 
SHENO MERRIN, J. et al. Biosorption of chromium VI using Rhizopus arrhizus. Indian Journal of Experimental Biology, v. 36, n. 10, p. 1052-1055, 1998.

SHETTY, Y. R.; HEGDE, A. M.; KAR, A. Observation of Teeth Eruption Timings Among a Group of Children Residing Near Uranium Mines. International Journal of Oral Health and Medical Research. 2(5):9-12, fev. 2016.

SILVA, C. M.; SOUZA, G. H.; AMARAL, R. S. Determinação da concentração de urânio em poços de abastecimento público da região urano-fosfática de Pernambuco. Physicae, v. 3, n. 3, p. 58-62, 1 jan. 2003.

SILVA, N. DA; JUNQUEIRA, V. C. A. Metodos de analise microbiologica de alimentos. Manual Técnico, p. 229, 1995.

SILVA, R. R. Biorremediação de solos contaminados com organoclorados por fungos basidiomicetos em biorreatores. 180 p. Tese (Doutorado em Botânica), Instituto de Botânica, Secretaria Meio Ambiente, São Paulo, 2009.

SOLAT, S.; REZA, R.; SOHEILA, Y. Biosorption of Uranium from Aqueous Solution by Live and Dead Aspergillus niger. Journal of Hazardous, Toxic, and Radioactive Waste, v. 18, n. 3, p. 04014016, jul. 2014.

SOUZA, A. M.; SILVEIRA, C. S.; PEREIRA, R. M. Contribuições dos metais provenientes das pilhas de rejeito da mina Osamu Utsumi a drenagens do Complexo Alcalino de Poços de Caldas, Minas Gerais. Geochimica Brasiliensis, v. 27, n. 1, p. 6376, 2013.

SPOON, M. Milling and Processing - How Uranium Mining Works. Disponível em: <https://science.howstuffworks.com/uranium-mining4.htm>. Acesso em: 7 fev. 2019.

SUH, J. et al. An Overview of GIS-Based Modeling and Assessment of MiningInduced Hazards: Soil, Water, and Forest. International journal of environmental research and public health, v. 14, n. 12, 2017.

SUJA, F. et al. Effects of local microbial bioaugmentation and biostimulation on the bioremediation of total petroleum hydrocarbons (TPH) in crude oil contaminated soil based on laboratory and field observations. International Biodeterioration \& Biodegradation 90. 115-122 2014.

SVECOVA, L. et al. Cadmium, lead and mercury biosorption on waste fungal biomass issued from fermentation industry. I. Equilibrium studies. Separation and Purification Technology, v. 52, n. 1, p. 142-153, 1 nov. 2006.

TAN, T.; CHENG, P. Biosorption of metal ions with Penicillium chrysogenum. 
Applied biochemistry and biotechnology, v. 104, n. 2, p. 119-128, fev. 2003.

TSEZOS, M.; GEORGOUSIS, Z.; REMOUDAKI, E. Mechanism of aluminum interference on uranium biosorption by Rhizopus arrhizus. Biotechnology and Bioengineering, v. 55, n. 1, p. 16-27, 5 jul. 1997.

TSEZOS, M.; VOLESKY, B. The mechanism of uranium biosorption by Rhizopus arrhizus. Biotechnology and Bioengineering, v. 24, n. 2, p. 385-401, fev. 1982.

USNRC. Conventional Uranium Mills. 2017. United States Nuclear Regulatory Comission. Disponível em: <https://www.nrc.gov/materials/uraniumrecovery/extraction-methods/conventional-mills.html>. Acesso em: 7 fev. 2019.

VÁZQUEZ-CAMPOS, X. et al. Uranium Binding Mechanisms of the AcidTolerant Fungus Coniochaeta fodinicola. Environmental Science and Technology, v. 49, n. 14, p. 8487-8496, 2015.

VALDMAN, E.; LEITE, S. G. F. Biosorption of Cd, Zn and Cu by Sargassum sp. waste biomass. Bioprocess Engineering, v. 22, n. 2, p. 171-173, 9 fev. 2000.

VAZQUEZ-CAMPOS, X. et al. Fodinomyces uranophilus gen. nov. sp. nov. and Coniochaeta fodinicola sp. nov., two uranium mine-inhabiting Ascomycota fungi from northern Australia. Mycologia, v. 106, n. 6, p. 1073-1089, 2014.

VDH. Frequently asked questions about uranium. 2016 . Virginia Department of Health. Disponível em: <http://www.vdh.virginia.gov/content/uploads/sites/12/2016/01/FAQ-Uranium2018.pdf>. Acesso em: 8 fev. 2019.

VERMA, A. et al. Biosorption of $\mathrm{Cu}$ (II) using free and immobilized biomass of Penicillium citrinum. Ecological Engineering, v. 61, p. 486-490, 1 dez. 2013.

VICENTE-VICENTE, L. et al. Nephrotoxicity of Uranium: Pathophysiological, Diagnostic and Therapeutic Perspectives. Toxicological Sciences, v. 118, n. 2, p. $324-$ 347, 1 dez. 2010.

VIDALI, M. Bioremediation. An overview. Pure Appl. Chem., Vol. 73, No. 7, pp. 1163-1172, 2001.

VISAGIE, C. M. et al. Identification and nomenclature of the genus Penicillium. Studies in Mycology, v. 78, n. 1, p. 343-371, 2014.

VOLESKY, B.; MAY-PHILLIPS, H. A. Biosorption of heavy metals by Saccharomyces cerevisiae. Applied Microbiology and Biotechnology, v. 42, n. 5, p. 797-806, 1995.

VOLESKY, B.; MAY, H.; HOLAN, Z. R. Cadmium biosorption by Saccharomyces 
cerevisiae. Biotechnology and Bioengineering, v. 41, n. 8, p. 826-829, 5 abr. 1993.

WAGNER, S. E. et al. Groundwater uranium and cancer incidence in South Carolina. Cancer Causes \& Control, v. 22, n. 1, p. 41-50, 16 jan. 2011.

WATANABE, K. Microorganisms relevant to bioremediation. Current Opinion in Biotechnology, v. 12, n. 3, p. 237-241, 2001.

WEIR, E. Uranium in drinking water, naturally. CMAJ : Canadian Medical Association journal = journal de l'Association medicale canadienne, v. 170, n. 6, p. 951-2, 16 mar. 2004.

WHITE, T. J. et al. Amplification and direct sequencing of fungal ribosomal rna genes for phylogenetics. PCR Protocols, p. 315-322, 1 jan. 1990.

WHO. The chemical toxicity of uranium. 2016. World Health Organization. Disponível em: <https://www.who.int/ionizing_radiation/pub_meet/en/Depluranium4.pdf?ua=1>. Acesso em: 11 fev. 2019.

WINDE, F.; ERASMUS, E.; GEIPEL, G. Uranium contaminated drinking water linked to leukaemia-Revisiting a case study from South Africa taking alternative exposure pathways into account. Science of The Total Environment, v. 574, p. 400421, 1 jan. 2017.

WUNDERLIN, D. The Suquía River Basin (Córdoba, Argentina): An Integrated Study on Its Hydrology, Pollution, Effects on Native Biota and Models to Evaluate Changes in water quality. Hdb env chem. 62: 207, 2018.

YANG, H. B. et al. Biosorption of uranium(VI) by a mangrove endophytic fungus Fusarium sp. \#ZZF51 from the South China Sea. Journal of Radioanalytical and Nuclear Chemistry, v. 291, n. 3, p. 1011-1016, 2012.

YILMAZ, N. et al. Polyphasic taxonomy of the genus Talaromyces. Studies in mycology, v. 78, p. 175-341, jun. 2014.

ZAFAR, S.; AQIL, F.; AHMAD, I. Metal tolerance and biosorption potential of filamentous fungi isolated from metal contaminated agricultural soil. Bioresource Technology, v. 98, n. 13, p. 2557-2561, 2007.

ZHENG, X. Y. et al. Effect of $\mathrm{pH}$ on uranium(VI) biosorption and biomineralization by Saccharomyces cerevisiae. Chemosphere, v. 203, p. 109-116, 1 jul. 2018.

ZUBBAIR, N. Studies on nutritional requirements of colletotrochum hibisci (tracy \& earle.). International Journal of Applied Biological Research, v. 1, n. 2, p. 55-61, 
2009. 